\title{
A Roadmap for Achieving Sustainable Energy Conversion and Storage: Graphene-Based Composites Used Both as an Electrocatalyst for Oxygen Reduction Reactions and an Electrode Material for a Supercapacitor
}

\author{
Peipei Huo ${ }^{1}$, Peng Zhao ${ }^{2}$, Yin Wang ${ }^{3}$, Bo Liu ${ }^{1, *}$, Guangchao Yin ${ }^{1}$ and Mingdong Dong ${ }^{3, *}$ \\ 1 Laboratory of Functional Molecules and Materials, School of Physics and Optoelectronic Engineering, \\ Shandong University of Technology, Xincun West Road 266, Zibo 255000, China; \\ peipeihuo@sdut.edu.cn (P.H.); yingc@sdut.edu.cn (G.Y.) \\ 2 School of Materials Science and Engineering, Shandong University of Technology, Xincun West Road 266, \\ Zibo 255000, China; 16509140463@stumail.sdut.edu.cn \\ 3 Interdisciplinary Nanoscience Center (iNANO), Aarhus University, DK-8000 Aarhus C, Denmark; \\ yin.wang@post.au.dk \\ * $\quad$ Correspondence: liub@sdut.edu.cn (B.L.); dong@inano.au.dk (M.D.)
}

Received: 27 November 2017; Accepted: 5 January 2018; Published: 10 January 2018

\begin{abstract}
Based on its unique features including 2D planar geometry, high specific surface area and electron conductivity, graphene has been intensively studied as oxygen reduction reaction (ORR) electrocatalyst and supercapacitor material. On the one hand, graphene possesses standalone electrocatalytic activity. It can also provide a good support for combining with other materials to generate graphene-based electrocatalysts, where the catalyst-support structure improves the stability and performance of electrocatalysts for ORR. On the other hand, graphene itself and its derivatives demonstrate a promising electrochemical capability as supercapacitors including electric double-layer capacitors (EDLCs) and pseudosupercapacitors. A hybrid supercapacitor (HS) is underlined and the advantages are elaborated. Graphene endows many materials that are capable of faradaic redox reactions with an outstanding pseudocapacitance behavior. In addition, the characteristics of graphene-based composite are also utilized in many respects to provide a porous 3D structure, formulate a novel supercapacitor with innovative design, and construct a flexible and tailorable device. In this review, we will present an overview of the use of graphene-based composites for sustainable energy conversion and storage.
\end{abstract}

Keywords: graphene-based composite; ORR; supercapacitor; electro-chemistry; electric double-layer (EDL) capacitance; pseudocapacitance

\section{Introduction}

Total energy consumption is increasing with the rapid growth of the global population and the accelerating development of the economy. In existing energy systems, $80 \%$ of energy consumption depends on fossil fuels such as oil, natural gas, and coal. Fossil fuels are not renewable, and their endless exploitation and consumption will inevitably lead to the depletion of resources. At the same time, emissions of toxic substances during the process of utilizing fossil fuels constitutes a serious threat to the environment [1]. The exploitation and utilization of conventional fossil fuels also varies strongly with natural conditions, such as the climate and geographic location. Innovation to convert from fossil fuels to sustainable energy, such as solar, wind, and biomass energy, is a high priority. It is 
urgent to use new technology to replace conventional energy conversion stereotypes [2]. Among them, fuel cells are excellent green solutions for next-generation energy conversion [3]. Besides, high power density energy storage devices are in pressing demand to meet challenges of solving the future energy crisis. Supercapacitors, with high power density, emerge as good candidates for energy storage $[4,5]$.

A fuel cell is a device that converts chemical energy directly into electrical energy in an electrochemical manner [6,7]. It enjoys many advantages. Firstly, since the electrochemical reaction process does not involve any combustion, its energy conversion efficiency is not limited by the Carnot cycle. In addition, when hydrogen is used as a fuel in a fuel cell, its only byproduct is water; even when small organic molecules such as methanol are used as a fuel, there are no emissions other than water and carbon dioxide. The amount of carbon dioxide emissions of fuel cells is far lower than those of the ordinary heat engine. As a result, fuel cells not only possess high energy conversion efficiency, but also produce much lower gas emissions, both in quantity and variety, compared with the most stringent present standards [8-10].

The electrochemical performance of a fuel cell depends largely on the cathodic ORR [11-14]. It is reasonable to assume that detailed study on ORR naturally leads to improvement of fuel cells' performance. The ORR is substantially determined by the catalytic activities of the cathode catalysts because of the sluggish reaction kinetics of ORR. In acidic electrolytes, the ORR occurs via the four-electron transfer (Equation (1)), or the two-electron transfer (Equation (2)) pathway. The overall four-electron transfer pathway is favorable due to its efficient utilization on electrons. In addition, it obviates the formation of any $\mathrm{H}_{2} \mathrm{O}_{2}$ species in the electrolyte that can cause degradation of membrane and ionomer:

$$
\begin{aligned}
& \mathrm{O}_{2}+4 \mathrm{H}^{+}+4 \mathrm{e}^{-} \rightarrow 2 \mathrm{H}_{2} \mathrm{O} \\
& \mathrm{O}_{2}+2 \mathrm{H}^{+}+2 \mathrm{e}^{-} \rightarrow \mathrm{H}_{2} \mathrm{O}_{2}
\end{aligned}
$$

Likewise, in alkaline conditions the ORR can occur via a four-electron transfer (Equation (3)) or a two-electron transfer (Equation (4)) reduction:

$$
\begin{gathered}
\mathrm{O}_{2}+2 \mathrm{H}_{2} \mathrm{O}+4 \mathrm{e}^{-} \rightarrow 4 \mathrm{OH}^{-} \\
\mathrm{O}_{2}+\mathrm{H}_{2} \mathrm{O}+2 \mathrm{e}^{-} \rightarrow \mathrm{HO}_{2}^{-}+\mathrm{OH}^{-}
\end{gathered}
$$

The ORR kinetics are dramatically more efficient in alkaline conditions, providing an opportunity to use non-platinum (non-Pt) metal catalysts, including metal-oxides, nitrogen-doped carbon nanostructures and so on $[15,16]$. Compared with Pt catalysts, these high cost-effective non-Pt catalysts that are mostly inclined to four-electron process would be better candidates for further industrial production if possible; while graphene-based composites dominate a large part among these catalytic species as well. Quite a few graphene and graphene-composite catalysts have been reported to provide an excellent activity and stability in alkaline conditions [17-23].

Supercapacitors, which combine the advantages of conventional dielectric capacitors (high power output) and batteries (high energy storage), have been recognized as some of the most important energy storage devices [24-26]. They have excellent power characteristics and cycle stability. The power density $\left(10^{3}-10^{5} \mathrm{~W} / \mathrm{kg}\right)$ is much higher than that of the lithium-ion battery $\left(10^{2}-10^{3} \mathrm{~W} / \mathrm{kg}\right)$. The charging time is so short that the charge-discharge of a large current can be carried out rapidly. The number of cycles can reach more than 500,000 times, leading to a service life for more than 10 years. They are widely used in new energy vehicles, consumer electronics products, new power generation systems, power grid systems and other fields. They can be generally categorized into two groups according to the charge storage patterns: EDLCs and pseudocapacitors [27-29]. EDLCs store charges in the double layer of the electrode-electrolyte interface, while pseudocapacitors store charges through rapid faradaic redox reactions.

The basic settings of supercapacitors include two electrodes, an ion-permeable membrane and an electrolyte. The characteristics of their electrode materials play a key role in influencing the 
performance of supercapacitors such as specific capacitance value, long term stability, and so on [30-32]. There are three main groups of electrode materials for supercapacitors: metal oxides/hydroxides, conducting polymers and carbon-based materials. The first two are not favorable for the kinetics but have high energy density, while carbon-based materials such as graphene, possess a higher power density and longer cycle lifes [33-38]. Recently, a novel electrochemical device, the hybrid supercapacitor (HS), has caught researchers' attention with its bifunctional (high power and energy densities) features stemming from combination of supercapacitor and Li-ion batteries (LIBs).

The discovery of graphene opened a new era of fundamental 2-dimensional (2D) science technology [39]. Graphene has a lot of distinctive features, including high aspect ratio, large specific surface, excellent electron conductivity, and good mechanical properties. The single-atom-thick graphene sheets with a 2D planar geometry will further facilitate electron transport that results in a good candidate for the more effective electrode materials in cathodic ORR [40]. As a result, graphene has been regarded as a promising electrode material for supercapacitors and HS as well [41].

A wide range of capabilities can be achieved by careful designing and integrating graphene-based materials. The application potential of fuel cells and supercapacitors that rely on ORR and electrode material is undergoing the substantial development with a pronounced progress. Understanding and modulating the characteristics of graphene and its composites may be the key to revolutionizing the performance of sustainable energy technologies and would be also the theme of this review. The current review will outline recent research on the role of graphene and its related application in ORR electrocatalysis (Table 1) as well as electrode materials for supercapacitors (Table 2). It will be divided into two main sections (Section 2 for ORR and Section 3 for supercapacitors, respectively), each with two or three sub-sections, based on the types of graphene-based materials being developed. In Section 2.1, the development of graphene-supported metal catalysts will be reviewed and discussed. In Section 2.2, the unique properties of graphene and its derivatives as standalone ORR electrocatalysts will be reviewed. Based on differences in mechanism, Section 3.1 will focus on graphene-based EDLCs. In this subsection, features of anti-restacking porous or 3D structure, novel design, synthesis methods and tailorable and flexible devices will be highlighted respectively. Section 3.2 will center around the graphene-based pseudocapacitance supercapacitor. $\mathrm{MnO}_{2}$, the star in this area, will be presented several times. Section 3.3 underlines the concept of HS and its advantages. Graphene greatly improves the electrochemical properties of HS devices as both cathodes and anodes.

\section{ORR Activity of Graphene-Based Catalysts}

\subsection{Graphene as Metal Support}

\subsubsection{Graphene as Pt-Based Electrocatalyst Support}

Fuel cells are believed to be the greener solutions for next generation power sources, whereas the pace of industrialization of fuel cells has been slowed down significantly by the sluggish kinetics of the cathodic ORR. Consequently, it is of high priority to investigate electrocatalysts for ORR at the cathode in fuel cells. In recent years, platinum (Pt) metal has been used as an electrocatalyst to avoid high overpotential and provide a significant ORR activity. On the other hand, the high quantity of catalyst loading is essential for electrode fabrication, which currently limits the Pt usage in practical applications because of its high price and scarcity. Moreover, in some cases, direct methanol fuel cell (DMFC) requires ORR catalysts with high methanol tolerance. Hence, there is an urgent demand for novel alternatives with lower cost, higher efficiency and excellent methanol-tolerance effect [42].

Ideal catalyst supports should possess features such as large surface areas, electronic conductivity, cycle stability and the quality to disperse nanoparticles (NPs) with uniform size. Graphene and its derivatives have recently emerged as a qualified candidates in this regard, with more and more reports on graphene-supported Pt NPs that demonstrate enhanced ORR activity and stability. 
Table 1. Electrocatalysts that are reviewed and their electrochemical performance.

\begin{tabular}{|c|c|c|c|c|c|c|c|c|}
\hline $\begin{array}{l}\text { [Ref.] Catalyst } \\
\text { Abbreviation }\end{array}$ & $\begin{array}{c}\text { Mass Activity } \\
(\mathrm{mA} / \mathrm{mg})\end{array}$ & $\begin{array}{c}\text { Current Density Specific } \\
\text { Density }\left(\mathrm{mA} / \mathrm{cm}^{2}\right)\end{array}$ & $\begin{array}{c}\text { ESCA BET } \\
\left(\mathrm{m}^{2} / \mathrm{g}\right)\end{array}$ & Onset Potential (V) & Peak Potential (V) & $\begin{array}{c}\text { Half-Wave } \\
\text { Potential (V) }\end{array}$ & $\begin{array}{c}4 \mathrm{e} \\
\text { Selectivity }\end{array}$ & Electrochemical Stability \\
\hline [43] G/FePt & - & 0.85 & - & - & - & 0.557 vs. $\mathrm{Ag} / \mathrm{AgCl}$ & - & $\begin{array}{c}\text { no change after } 10,000 \text { cycles in } \\
0.4-0.8 \mathrm{~V} \text { range }\end{array}$ \\
\hline [44] $\mathrm{Fe}_{3} \mathrm{O}_{4} / \mathrm{N}-\mathrm{GAs}$ & - & -2.56 & - & -0.19 vs. $\mathrm{Ag} / \mathrm{AgCl}$ & - & - & $3.72-3.95$ & $79.3 \%$ current retention after $20,000 \mathrm{~s}$ \\
\hline [45] $\mathrm{MnCo}_{2} \mathrm{O}_{4} / \mathrm{N}-\mathrm{rmGO}$ & - & 151 & - & 0.95 vs. RHE & 0.88 vs. RHE & - & $\sim 3.9$ & $\begin{array}{l}3.5 \% \text { decrease in current density } \\
\text { over } 20,000 \mathrm{~s}\end{array}$ \\
\hline $\begin{array}{l}\text { [46] } \mathrm{MN}_{4} \text { type cobalt(III) } \\
{[47](\mathrm{G}-\text { dye-FeP })_{n} \mathrm{MOF}}\end{array}$ & - & - & - & - & $\begin{array}{l}-0.04 \text { vs. } \mathrm{Ag} / \mathrm{AgCl} \\
-0.23 \text { vs. } \mathrm{Ag} / \mathrm{AgCl}\end{array}$ & - & $\begin{array}{l}4.04 \\
\sim 4\end{array}$ & - \\
\hline [48] N-Graphene & - & -0.78 & - & - & - & - & $3.6-4$ & $\begin{array}{l}\text { no obvious current decrease after } \\
200,000 \text { cycles in }-1.0-0 \text { V range }\end{array}$ \\
\hline [49] PDDA-Graphene & - & - & - & -0.15 vs. SCE & -0.35 vs. SCE & - & $3.5-4$ & $\begin{array}{l}\text { much slower decrease than the Pt/C } \\
\text { and leveled off after } 17,000 \mathrm{~s}\end{array}$ \\
\hline [50] N-Doped Graphene & - & $\begin{array}{l}-2.4(\mathrm{NG}-\mathrm{M}) \\
-2.6(\mathrm{NG}-\mathrm{T}) \\
-3.3(\mathrm{NG}-\mathrm{C})\end{array}$ & - & $\begin{array}{l}-0.07(\mathrm{NG}-\mathrm{M}) \\
0(\mathrm{NG}-\mathrm{T}) \\
0(\mathrm{NG}-\mathrm{C})\end{array}$ & $\begin{array}{l}-0.31(\mathrm{NG}-\mathrm{M}) \\
-0.22(\mathrm{NG}-\mathrm{T}) \\
-0.28(\mathrm{NG}-\mathrm{C})\end{array}$ & - & 3.55 & $\begin{array}{l}\text { no significant decrease in current } \\
\text { density after } 2000 \text { cycles }\end{array}$ \\
\hline [51] GNPCSs & - & - & 911 & - & - & - & $3.78-3.98$ & $94 \%$ retention over $28,000 \mathrm{~s}$ \\
\hline [52] GZx & - & - & 917 for GZ80 & 0.88 vs. RHE & - & 0.75 & 3.2 & $\begin{array}{l}\text { negligible penalty in } \mathrm{E}_{1 / 2} \text { after } \\
5000 \text { cycles }\end{array}$ \\
\hline [53] G-ANF-1 & 35 & 1.3 & 203(G-ANF-1) & 0.73 vs. RHE & 0.63 & - & 3.2 & - \\
\hline [54] N,P-GCNS & - & 5.56 & 900.2 & 1.01 & 0.85 vs. RHE & - & 3.96 & $\begin{array}{l}4.5 \% \text { performance attenuation } \\
\text { after } 16,000 \mathrm{~s}\end{array}$ \\
\hline $\begin{array}{c}\text { [55] NSG } \\
{[56] \text { N-GQD }}\end{array}$ & - & - & $\begin{array}{c}319.93 \\
-\end{array}$ & - & $\begin{array}{c}-0.22 \text { vs. SCE } \\
-0.27\end{array}$ & -0.23 & $\begin{array}{c}3.52-3.83 \\
3.6-4.4\end{array}$ & $\begin{array}{l}94.3 \% \text { current retention after } 55,000 \mathrm{~s} \\
\text { no obvious decrease after } 2 \text { days }\end{array}$ \\
\hline [57] BN-GQD/G30 & - & $\sim 11.1$ & - & $\sim 0$ vs. $\mathrm{Ag} / \mathrm{AgCl}$ & - & - & 3.93 & - \\
\hline [58] GQD/GNR & - & 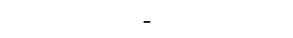 & - & & -0.19 vs. $\mathrm{Ag} / \mathrm{AgCl}$ & & 3.91 & $1 \%$ current decrease after $26 \mathrm{~h}$ \\
\hline [59] GC-NLs & - & -4.80 & - & 0.85 vs. RHE & - & 0.72 & $3.6-3.8$ & - \\
\hline
\end{tabular}


Table 2. Electrode materials that are reviewed and their capacitive performance.

\begin{tabular}{|c|c|c|c|c|c|c|c|c|}
\hline $\begin{array}{l}\text { [Ref.] Electrode Material } \\
\text { Abbreviation }\end{array}$ & $\begin{array}{c}\text { BET } \\
\left(\mathrm{m}^{2} / \mathrm{g}\right)\end{array}$ & $\begin{array}{c}\text { Electrical } \\
\text { Conductiviy (S/m) } \\
\end{array}$ & Specific Capacitance & Stability/Capacitance Retention & $\begin{array}{c}\text { Rate Capability Rate } \\
\text { Performance }\end{array}$ & Energy Density & Power Density & $\begin{array}{c}\text { Equivalent Series } \\
\text { Resistance }\end{array}$ \\
\hline [60] NGA & 830 & 0.8 & $223 \mathrm{~F} / \mathrm{g}$ & $8 \%$ decrease after 2000 cycles & - & - & - & - \\
\hline [61] GA@NF & 463 & 71.4 & $366 \mathrm{~F} / \mathrm{g}$ & $60 \%$ retention after 2000 cycles & - & - & - & $0.45 \Omega$ \\
\hline [62] curved graphene & - & - & 151.4 F/g@1 A/g & - & $\begin{array}{l}\text { Completely recharged } \\
\text { in less than } 2 \mathrm{~min}\end{array}$ & $90 \mathrm{Wh} / \mathrm{kg}$ & - & - \\
\hline [63] graphene material & 320 & 100 & $205 \mathrm{~F} / \mathrm{g}, 64 \mu \mathrm{F} / \mathrm{cm}^{2}$ & $90 \%$ retention after 1200 cycles & in Iess tnan 2 min & $28.5 \mathrm{Wh} / \mathrm{kg}$ & $10 \mathrm{~kW} / \mathrm{kg}$ & $3.2 \Omega$ \\
\hline [64] cMR-rGO th & 1040 & - & $210 \mathrm{~F} / \mathrm{g}$ & $96 \%$ retention after 20,000 cycles & - & - & - & \\
\hline [65] blade-rGO & - & - & $250 \mathrm{~F} / \mathrm{g}$ & $90 \%$ retention over 4000 cycles & - & - & - & $7.5-16 \Omega$ \\
\hline [66] RMGO & - & & $247.3 \mathrm{~F} / \mathrm{g}$ & No degradation in performance after 1500 cycles & - & - & - & - \\
\hline [67] p-doped MGB & 346 & $6.5 \mathrm{~S} / \mathrm{cm}$ & $206 \mathrm{~F} / \mathrm{g}$ & $96 \%$ retention after 10,000 cycles & - & - & - & - \\
\hline [68] LRGONR & 190 & - & $1042 \mathrm{~F} / \mathrm{g}$ & $97 \%$ retention over $3000 \mathrm{GCD}$ cycles & - & $15.06 \mathrm{Wh} / \mathrm{kg}$ & - & $0.48 \Omega$ \\
\hline [69] B-doped Graphene & 466 & - & $200 \mathrm{~F} / \mathrm{g}, 43 \mu \mathrm{F} / \mathrm{cm}^{2}$ & $95 \%$ retention after 4500 cycles & - & - & - & $0.8 \Omega$ \\
\hline [70] Si-rGO & - & - & $184.4 \mathrm{~F} / \mathrm{g}$ & 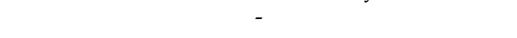 & - & - & $107 \mathrm{~kW} / \mathrm{kg}$ & $0.61 \Omega$ \\
\hline [71] SPG & 418 & - & $16.2 \mu \mathrm{F} / \mathrm{cm}^{2}$ & $87 \%$ retention after 10,000 cycles & $\begin{array}{l}2.3 \mathrm{~min} \text { for one } \\
\text { charge-discharge cycle }\end{array}$ & $21.4 \mathrm{Wh} / \mathrm{kg}$ & - & - \\
\hline [72] ErGO-NCA & - & - & $160 \mathrm{~F} / \mathrm{g}, 57.1 \mathrm{mF} / \mathrm{cm}^{2}$ & $94.3 \%$ retentioan after 20,000 cycles & tiangenas - & - & - & - \\
\hline [73] PPy/RGO/MWCNTs & - & - & $25.9 \mathrm{~F} / \mathrm{cm}^{3}$ & $9.6 \%$ decay over 3000 cycles & - & $0.94 \mathrm{mWh} / \mathrm{cm}^{3}$ & - & $0.7 \Omega$ \\
\hline [74] GMC or GMP & - & - & $380 \mathrm{~F} / \mathrm{g}$ & 95-96\% capacitance retention after 1000 cycles & - & 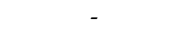 & - & $41 \Omega$ or $27 \Omega$ \\
\hline [75] $\mathrm{MnO}_{2} / \mathrm{NRGO}$ & - & - & $522 \mathrm{~F} / \mathrm{g}$ & 3.7\% decrease after applying $4000 \mathrm{CVs}$ & - & - & & $0.40 \Omega$ \\
\hline$[76] \mathrm{Ni}(\mathrm{OH})_{2}-\mathrm{MnO}_{2}-\mathrm{RGO}$ & 147 & - & $1985 \mathrm{~F} / \mathrm{g}$ & $75 \%$ capacity retention after 2000 cycles & - & $54.0 \mathrm{Wh} / \mathrm{kg}$ & $1016 \mathrm{~W} / \mathrm{kg}$ & - \\
\hline [77] Graphene $/ \mathrm{MnO}_{2}$ & 392 & - & $130 \mathrm{~F} / \mathrm{g}, 1.42 \mathrm{~F} / \mathrm{cm}^{2}$ & $\begin{array}{l}\text { Capacity decrease from } 29.8 / \mathrm{g}-27.8 \mathrm{~F} / \mathrm{g} \\
\text { after } 500 \text { cycles }\end{array}$ & - & $6.8 \mathrm{Wh} / \mathrm{kg}$ & - & $2.41 \Omega$ \\
\hline$[78] \mathrm{Co}_{3} \mathrm{O}_{4} /$ VAGN & - & - & $3480 \mathrm{~F} / \mathrm{g}$ & & - & $80 \mathrm{Wh} / \mathrm{kg}$ & $20 \mathrm{~kW} / \mathrm{kg}$ & 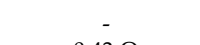 \\
\hline [79] $\mathrm{CeO}_{2}$-NRGO & - & - & $230 \mathrm{~F} / \mathrm{g}$ & $94.1 \%$ retention for 4000 cycles tests & - & - & - & $0.43 \Omega$ \\
\hline$[80] \alpha-\mathrm{Fe}_{2} \mathrm{O}_{3} / \mathrm{rGO}$ & 38.04 & - & $930.6 \mathrm{~F} / \mathrm{g}$ & $70 \%$ retention after 1000 cycles & - & - & - & $1.64 \Omega$ \\
\hline
\end{tabular}


However, it often faces a big issue that the basal planes of graphene surfaces are not beneficial for connection with Pt NPs. This can make it harsh to load homogeneously dispersed NPs of uniform size, resulting in agglomeration or NPs deposition restricted to edge sites. Fortunately, it can be overcome by covalent or noncovalent functionalization procedures that render a uniform dispersion of NPs. Yang et al. functionalized the surface of graphene oxide (GO) with polydiallyldimethyl-ammonium chloride (PDDA) [81]. This approach displayed uniform dispersion of ca. 2-3 nm NPs that possess excellent electrochemical stability.

One solution to $\mathrm{Pt}$ loading reduction could be accomplished by structuring Pt-bimetallic alloy surfaces [82]. However, in these binary PtM $(\mathrm{M}=\mathrm{Co}, \mathrm{Ni}, \mathrm{Fe}, \mathrm{Mn})$ studies, the catalyst NPs prepared from the in situ growth method are not sufficient to meet the requirements of uniform size and controllable morphology. Meanwhile, with the progress made in solution-phase synthesis of monodisperse NPs, the integration of NPs on the graphene nanosheets has been considered as a better way for the promotion of catalytic activity than that of only NPs as catalysts. Sun et al. demonstrated (Figure 1) that FePt NPs with uniform size self-assembled on graphene. Higher ORR activity was achieved by these graphene/FePt NPs, compared with commercial carbon/Pt NPs. Regarding the stability, the graphene/FePt NPs barely displayed any performance deterioration after 10,000 potential sweeps [43].
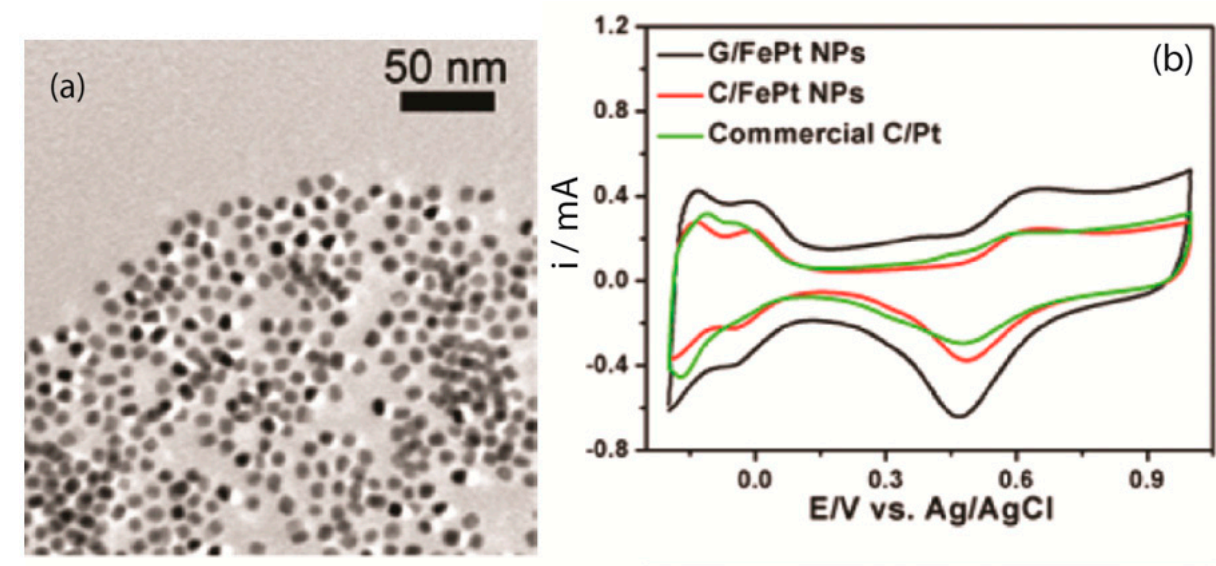

(c)
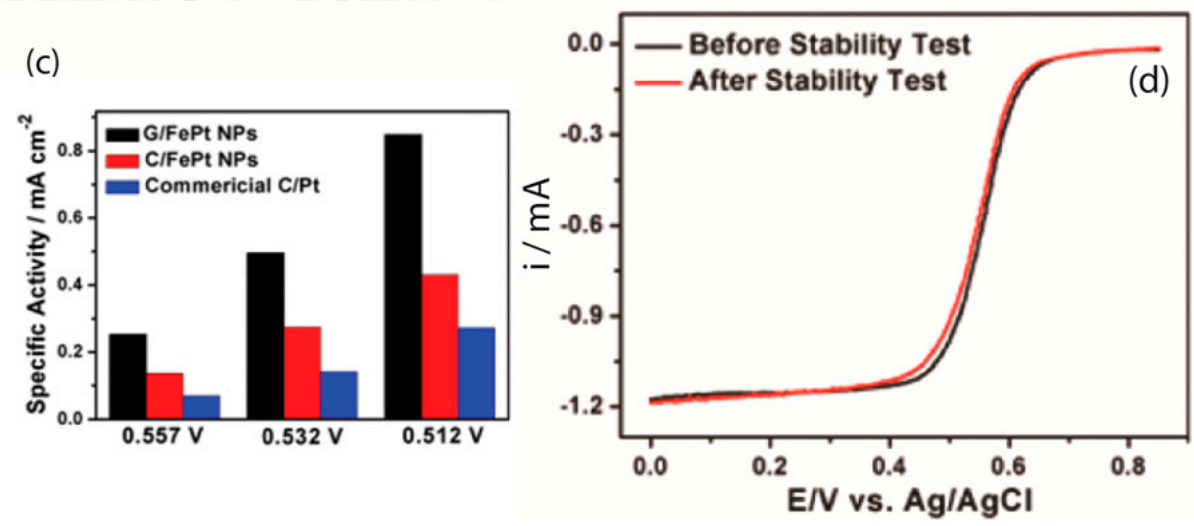

Figure 1. (a) TEM image of the $\mathrm{Fe}_{58} \mathrm{Pt}_{42} \mathrm{NPs}$ assembled on the graphene surface. (b) Cyclic Voltammograms (CVs) in $\mathrm{N}_{2}$-saturated $0.1 \mathrm{M} \mathrm{HClO}_{4}$ solution. (c) ORR specific activities of the $\mathrm{G} / \mathrm{FePt}, \mathrm{C} / \mathrm{FePt}$, and commercial C/Pt catalysts. (d) ORR polarization curves of the G/FePt NPs before and after 10,000 potential sweeps (reprinted from [43] with permission from the American Chemical Society. Copyright 2012).

\subsubsection{Graphene as Pt-Free Metal Electrocatalyst Support}

Pt-based cathode electrocatalysts easily to suffer from the crossover effect and CO poisoning. Another factor that cannot be overlooked is that the high cost and scarcity of Pt and its alloys slow down the pace for further development. A further improvement for replacement of Pt-based ORR 
catalyst is Pt-free, non-precious metal supported by an appropriate material. This can be referred to as the ultimate goal of ORR electrocatalysis research field as it would allow the elimination of $\mathrm{Pt}$ from the cathode electrode entirely. Inspired by this motivation, a variety of alternatives composed of non-Pt metals or metal oxides have been intensively investigated. Graphene-based materials have naturally been an essential part in the non-Pt catalyst investigations, where graphene nanosheets can act as the support for sintering systems by utilizing the beneficial characteristics of graphene sheets, namely macroporosity and multidimensional electron shuttling routes. Müllen et al. reported three-dimensional (3D) N-doped graphene aerogel-supported $\mathrm{Fe}_{3} \mathrm{O}_{4} \mathrm{NPs}\left(\mathrm{Fe}_{3} \mathrm{O}_{4} / \mathrm{N}\right.$-GAs) which can work as cathode electrocatalysts for ORR. The $\mathrm{Fe}_{3} \mathrm{O}_{4} / \mathrm{N}-\mathrm{GAs}$ displayed a hierarchical structure with macroporous graphene sheets as support and monodisperse $\mathrm{Fe}_{3} \mathrm{O}_{4} \mathrm{NPs}$ as active sites. A more positive onset potential for ORR and higher cathodic current density are strong evidence for the excellent ORR activity. The linear sweep voltammograms (LSVs) of $\mathrm{Fe}_{3} \mathrm{O}_{4} / \mathrm{N}-\mathrm{GAs}$ disclosed a favorable four-electron reaction pathway. In addition, $\mathrm{Fe}_{3} \mathrm{O}_{4} / \mathrm{N}-\mathrm{GAs}$ surpassed commercial $\mathrm{Pt} / \mathrm{C}$ catalyst in stability test [44].

The problem with the above research is that the activity of ORR catalysts is still inferior to Pt. To search for non-Pt alternative electrocatalysts with equal or even higher activity, Regier et al. synthesized a $\mathrm{MnCo}_{2} \mathrm{O}_{4} /$ graphene hybrid with a spinel structure for high ORR performance. Since $\mathrm{MnCo}_{2} \mathrm{O}_{4}$ has higher activity than pure $\mathrm{Co}_{3} \mathrm{O}_{4}$ and stronger coupling with $\mathrm{N}$-doped graphene, the $\mathrm{MnCo}_{2} \mathrm{O}_{4} /$ graphene displayed a better activity than the $\mathrm{Co}_{3} \mathrm{O}_{4} /$ graphene hybrid. In the electrochemical performance tests, it showed a more positive peak potential for ORR and a higher electron transfer number than the counterparts as physical blending of $\mathrm{N}$-doped graphene sheets and $\mathrm{MnCo}_{2} \mathrm{O}_{4} \mathrm{NPs}$ [45].

Except got the usage of transition metal complexes mentioned above, there have been reports on using macrocyclic rings with nitrogen pockets with either Co or Fe as active catalysts for ORR. Ghosh et al. synthesized a Co (III) amido-macrocyclic complex along with graphene which displayed an ORR performance comparable with previous non-precious metal catalysts supported on graphene. Not only a four-electron ORR process but also a more positive peak potential occurred due to the synergistic effect between graphene and the complexes. The main reason for enhanced electrocatalytic activity is the higher electron conductivity introduced by graphene as a support material [46].

Fe-porphyrins have been attracting attention based on their ORR performance in biological systems. The epoxy and hydroxyl functional groups on both sides of the GO sheet can act as structural nodes. A meaningful question one may consider would be whether metal porphyrin supported on graphene can work as a candidate for replacement of Pt-based electrode. Therefore Loh et al. utilized reduced graphene oxide (rGO) sheets with functional groups on the basal plane; they can work as struts to connect metalloporphyrin nodes to construct the hybrid as graphene/metal organic framework. In the meanwhile, the oxygenated functional groups on rGO can catalyze ORR because these are an excellent electron transfer intermediator [47].

\subsection{Graphene as Standalone ORR Catalyst}

\subsubsection{Nitrogen-Doped Graphene}

Given that graphene-based material has intrinsic advantages, there is a large amount of research on such materials and their applications as standalone electrocatalysts for ORR. Particularly, graphene has a very limited activity, often displaying selectivity to the unfavorable two electron reduction mechanism. In this regard, heteroatom-doped graphenes like nitrogen-doped ones in most cases are actively investigated.

In nitrogen-doped graphene (NDG), nitrogen atoms can generate a net positive charge on adjacent carbon atoms in the graphene sheets so as to accept electrons from the anode for facilitating the ORR. Efforts have been made to introduce nitrogen into graphene sheets by utilizing electron accepting features of nitrogen atoms, which render an improved electrocatalytic activity. For example, Dai et al. investigated the chemical vapor deposition (CVD)-deposited NDG sheets for ORR at the cathode in alkaline solution. The N-graphene film consists of only one or a few layers of the graphene sheets 
with smooth surface. The layer thickness was analyzed to be in the range of $0.9-1.1 \mathrm{~nm}$. The NDG displayed a much higher electrocatalytic activity, cycle stability, and tolerance to poison effects than the commercial Pt-based electrodes for ORR [48].

In addition to nitrogen dopant, these authors further developed carbon-based ORR catalysts by PDDA to produce positive sites to attract oxygen in the nitrogen-free graphene plane. The main principle is that the positively charged PDDA is capable of electron attracting that allows to create a positive charge on adjacent atoms in the basal planes of graphene via the intermolecular charge transfer. The PDDA-functionalized graphene was proved to possess significantly improved electrocatalytic activities toward ORR [49].

Self-assembly technology is also applied to synthesis of NDGs. A bottom-up approach assembling from small precursor molecules was recently introduced to synthesize graphene or NDG. Zhu et al. fabricated NDG using a natural and harmless fruit acid, $\alpha$-hydroxyacids (AHAs), as carbon sources and melamine as nitrogen source by this bottom-up approach. The acid groups in fruit acids can react with amino groups of melamine to strengthen the bonding between carbon source and nitrogen source (Figure 2). The pronounced ORR catalytic activity and high durability were exhibited by the as-prepared NDGs due to their high specific surface areas, high nitrogen contents, and mesoporous architectures [50].

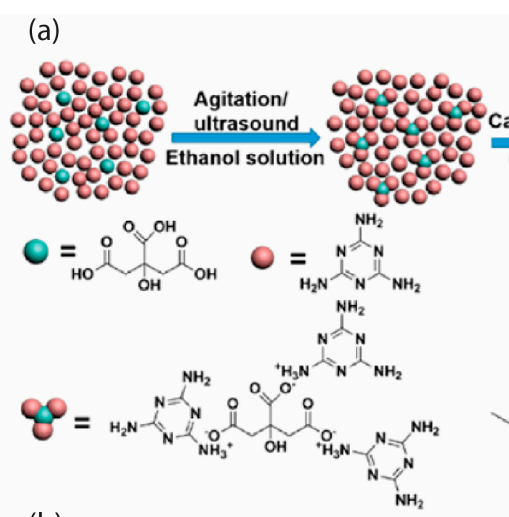

(b)

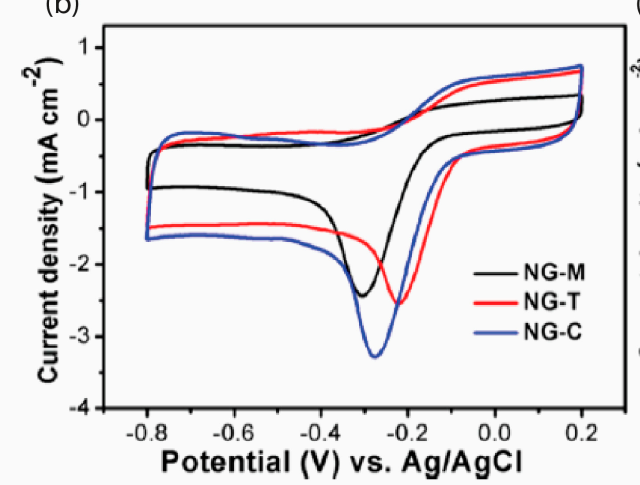

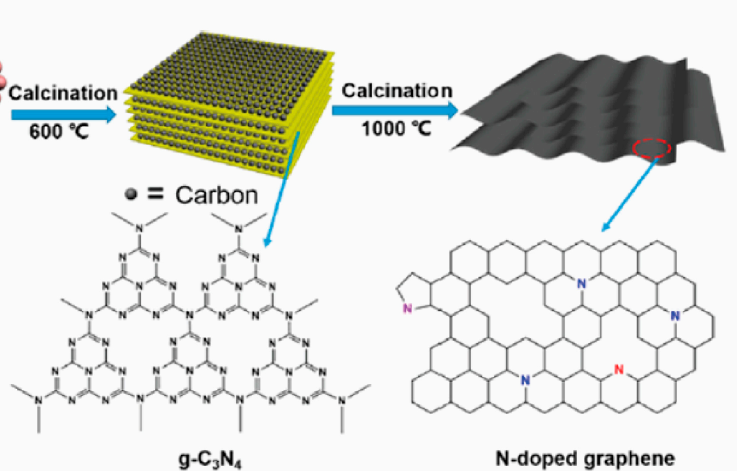

(c)

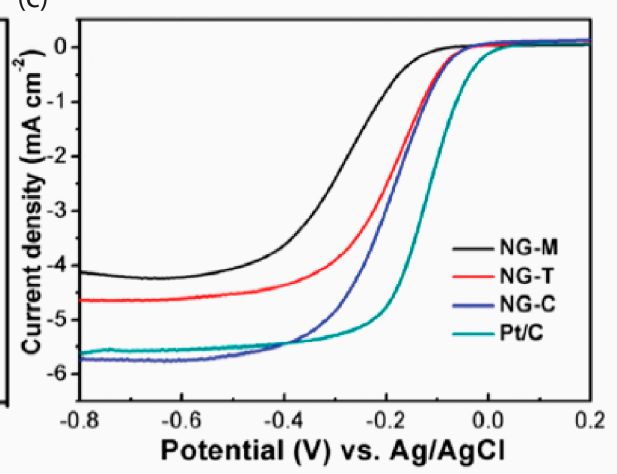

Figure 2. (a) Proposed synthetic protocol for N-doped graphene. (b) CV plots of NG-M, NG-T, and NG-C. (c) LSV curves of ORR on NGs and commercial Pt/C at a scan rate of $5 \mathrm{mV} / \mathrm{s}$ at $1600 \mathrm{rpm}$. (Reprinted from reference [50] with permission from the American Chemical Society. Copyright 2015).

Another approach to producing NDG is thermal treatment of nitrogen-rich metal-organic frameworks. Nitrogen-containing metal-organic frameworks especially can act as both a precursor for carbon and a source of nitrogen. Zeolitic imidazolate frameworks (ZIFs) are good options compared with other metal-organic frameworks for the preparation of catalyst due to their high thermal and chemical stability. Finally they are able to form microporous carbon frameworks through heat treatment. For example, Zong et al. demonstrated ZIF-GO composites with 2D sandwich-like structures by 
growing ZIF-8 on GO in situ to generate NDC nanosheets [51]. Hareesh et al. further demonstrated that an interconnected porous network with a better ORR activity and cyclic stability can be fabricated by GO wrapping ZIF-8 microcrystals as efficient precursors. The formation of porous carbon network was attributed to the GO sheets that were surrounding ZIF-8 crystals, acting as a protection layer in order to reduce the loss of nitrogen upon heat treatment. Importantly, this precursor can be simply obtained by one-pot synthesis at room temperature. An additional advantage of precursor network is structural heteroporosity to favorably provide active sites for ORR [52].

There is a change in density of states when modulation of graphene happens by heteroatom doping or fictionalization. In the meanwhile, it would also generate distinct chemical sites at the hybrid surface so as to provide the physisorption or chemisorption opportunities to redox species in the electrolyte. Besides, the carbon morphology may be changed as well. For example, density of edges usually has an impact on electrochemical behavior in catalysis. Testing the electrochemical behavior of graphitic edges (GEs) is thus of interest. Colavita et al. revealed that it is feasible to tune ORR activity and obtain higher onset potentials by modifying the carbon matrix exclusively without heteroatom dopants. Catalytic activity is closely associated with carbon matrix structure that has a possibility to have the effect of chemical doping simulated or screened [53].

\subsubsection{Dual-Doped Graphene as ORR Catalyst}

NDGs have played an important role in electrocatalysis of ORR. However, their performance was largely hindered by the small loading of nitrogen dopants. However, increasing doping percentage and simultaneous co-doping carbon with nitrogen and other heteroatoms would be an alternative to get rid of drawbacks of nitrogen dopants. In fact, there have been some studies showing the existence of synergistic effects between the co-doped heteroatoms. Based on these findings, it is reasonable to speculate that binary or ternary element-doped nanocarbons could lead to performance improvement. Gou et al. reported the graphene/carbon nanosheets with nitrogen and phosphorus codoping (N,P-GCNS). N,P-GCNS was produced through the process of pyrolysis of a hydrogel that consists of GO, polyaniline (PANi) and phytic acid (PA). GO nanosheets played a dominant role in these three factors. The conformal coating of PANi and PA was structurally directed by GO nanosheets that acted as the precursor of graphene as well. As a consequence, the N,P-GCNS showed a much better electrocatalytic performance compared with the only single $\mathrm{N}$-doped or P-doped counterparts respectively, owing to the synergetic effects of $\mathrm{N}$ and $\mathrm{P}$ dopants, good conductivity, high active surface area, and porous structure for mass transportation [54].

In the dual-heteroatom doping of nitrogen (N) and sulfur (S), density functional theory (DFT) analysis indicates that it demands less formation energy to codope $\mathrm{N}$ and $\mathrm{S}$ into graphene at the same time than the total energy for separate doping of the respective atoms. As a result, there is an increase in charge densities because of the synergy between $\mathrm{N}$ and $\mathrm{S}$ that can influence electronic properties. It is also the reason why oxygen adsorption and reactivity can be improved. From the structural perspective, graphene frameworks are porous with a relatively high surface area. Interconnected pores in this $3 \mathrm{D}$ architecture facilitate mass transportation. High electrical conductivity and low density can also significantly enhance catalytic activity. In addition, most doped heteroatoms synthesis would involve in toxic reagents via complicated routes, preparation of such porous frameworks is no exception, also involving a sacrificial templates elimination process by strong chemical etching. Fortunately, a facile and environmentally benign strategy has been developed without template for the synthesis of 3D porous graphene architecture. Along the edges of graphene sheets, the in situ stimulation can expand and self-assemble by the linkage between different sheets. Mu et al. reported this kind of non-template strategy to introduce $\mathrm{N}$ and $\mathrm{S}$ into 3D porous graphene simultaneously. A single-row pyrolysis was used to prepare the catalyst, blending GO and biomass. The biomass not only provided both sources of $\mathrm{N}$ and $\mathrm{S}$, but also influenced the ORR as well as structural formation. The catalyst demonstrated ORR kinetic activity comparable to $\mathrm{Pt} / \mathrm{C}$. Additionally, its cycle stability and resistance to $\mathrm{CO}$ poisoning and fuel oxidation intermediates were both superior to $\mathrm{Pt} / \mathrm{C}$ [55]. 


\subsubsection{Graphene/Carbon Nanostructure Composite}

In respect of exploring the electrocatalytic activity of other forms of graphene, Qu et al. have reported that $\mathrm{N}$-doped graphene quantum dots (GQDs) functionalized with oxygen-rich groups displayed outstanding ORR activities [56]. More recently, mixing GQDs with heteroatom-doped graphene has been reported to show synergistic effects to improve the electrocatalytic activity for ORR [57]. Dai et al. developed a new type of ORR catalysts based on GQDs supported on graphene nanoribbons (GNRs). The catalysts were simply synthesized by a one-step reduction pathway. Oxygen was reduced through a highly selective 4-electron ORR process, leading to excellent electrochemical performance in limiting current density and low overpotential together with stability in alkaline media. To be specific, LSVs for GQD-GNR hybrid electrodes shows that the onset potential of ORR is even more positive than that of $\mathrm{Pt} / \mathrm{C}$. The half-wave potential of the GQD-GNR electrode is comparable to that of $\mathrm{Pt} / \mathrm{C}$ catalyst but much better than the separated GQD and GNR. In fact, the contact between GQD and GNR plays an important role in efficient charge transfer, leading to the enhanced ORR performance [58].

Both graphene and carbon nanotubes (CNTs) can function as suitable supports for anchoring surface active moieties for ORR, with increased dynamics generally rendered by doping with heteroatoms such as nitrogen, phosphorus, and sulfur. Chen et al. reported the synthesis of nitrogen and sulfur codoped graphene/CNT nanocomposites that lead to enhanced activity and excellent stability toward the ORR. The combination of these two "platforms" was investigated to increase a great number of surface areas for the beneficial ORR catalysis, where CNTs increases conductivity in the resultant 3D architectures with surface chemistry of graphene. Meanwhile, synergistic effect between heteroatom-doped graphene and CNTs also makes a contribution. They demonstrated promising ORR enhancements provided by co-doping effect as well as optimized nanocomposite configuration [59].

\section{Graphene-Based Materials in Supercapacitor Applications}

\subsection{Graphene-Based EDL Supercapacitor}

\subsubsection{Anti-Restacking Porous or 3D Architecture}

Double-layer supercapacitors store energy by forming double layer charges on the interface of a porous electrode material with high surface area and an electrolyte. Therefore, the specific surface area, pore size distribution, electrical conductivity and electrochemical stability of the electrode material will directly affect the device performance. However, the strong Van der Waals force between neighboring layers makes it easy for separated graphene layers to restack, leading to aggregated structures. This on the large scale hinders electrolyte transfer and ion accessibility, especially in ion liquids with a high viscosity. A potential solution to this aggregation is to synthesize graphene with porous or 3D structure [60]. EDL storage depends on the charge accumulation at electrode surface. Consequently, large surface area materials, such as aerogels with curved morphology and solvated stacking-free feature, are produced.

In most cases graphene electrode material obtained by chemical reduction method or thermal reduction method can show good performance of the capacitor. But its structure is still too tight to provide enough channels for conducting electrolyte ions in the electrodes. To a large extent it will limit the material capacitor performance and the rate performance. Han et al. prepared the nitrogen-doped graphene aerogels (NGA), which has an interconnected porous structure with a high surface area $\left(830 \mathrm{~m}^{2} / \mathrm{g}\right)$. The NGA displayed excellent capacitance value $(223 \mathrm{~F} / \mathrm{g}$ at $0.2 \mathrm{~A} / \mathrm{g})$ and long-term cycling performance. The promising electrochemical performance can be attributed to the beneficial porous network, favorable electron transport, high nitrogen content and the uniform distribution of functional groups bonded covalently on the basal sheets of graphene [60].

Unfortunately, there are still some challenges that graphene aerogel faces. Besides self-aggregation of graphene sheets, contact resistance between graphene and the metal current collector could also 
become the main factor, limiting the capacitive performance. By introducing nickel foam, freeze-drying and the following heat treatment of GO hydrogel-nickel foam hybrid precursor, 3D graphene aerogels with high loading, high porosity and high conductivity were deposited on the nickel foam. High rate capability, long-term cyclic stability, and a specific capacitance allow the final graphene aerogel/nickel foam electrode to have a significant EDL capacitive behavior [61].

The key to high energy density in graphene-based supercapacitors is to fully utilize the high intrinsic surface capacitance and specific surface area of each single layer of graphene, which can be achieved by curved graphene. The curved graphene structure could be prepared by using a fluidized bed technique with GO aqueous solution as raw material. The as-made material is hard to stack and has a pore size of 2-25 nm. The curved graphene sheets have a large specific surface area and more mesopores which are beneficial to ion transport of ionic liquids. With a mesoporous curved graphene material as electrode material, excellent electrochemical performance was obtained in ionic liquids, especially for capacitance values and energy densities [62].

After oxidation, GO can disperse in electrolyte as separate single layers, but the subsequent reduction of GO in electrolyte will cause the dispersed single layer to restack forming aggregated structures, which on a large scale makes the specific surface area of graphene shrink. Instead of aqueous solution reduction, Chen et al. used a gas-solid reduction. Although a certain level of aggregation and an overlap of rGO sheets remained, the degree of aggregation was much less than the aqueous reduction pathway. The as-prepared electrode material can increase the adsorption of electrolyte ions, leading to a larger specific capacitance value. As a result, this electrode material could achieve the highest specific capacitance as $205 \mathrm{~F} / \mathrm{g}$ at $1.0 \mathrm{~V}$ in aqueous solution and remained $90 \%$ of its initial value through 1200 cycles [63].

In aqueous solution synthesis, graphene layers are susceptible to a high degree of aggregation and thus make it difficult to maintain the material characteristics and advantages. Choi et al. considered that the interbedded water molecules between the dried GO plays a critical role as a mediator for the restacking, while melamine resin (MR) monomers can provide a good opportunity to treat GO so that hydrogen bonding involved in such interbedded water could be removed. Porous restacking-inhibited GO sheets precipitated after MR monomers were added, forming a graphene-based composite with an outstanding specific surface area of $1040 \mathrm{~m}^{2} / \mathrm{g}$. Owing to such high surface area, the resultant graphene-based composite can achieve a specific capacitance of $210 \mathrm{~F} / \mathrm{g}$, remaining $\sim 100 \%$ capacitance after 20,000 cycles [64].

The main challenge in employing GO as a component in supercapacitors is to eliminate the oxygenated groups from GO sheets. Graphitizing in the process of reduction is another limitation that needs to be considered as well. The liquid crystals (LCs) of graphene oxide are developed to deal with it. Due to alignment of GO nanosheets at a high concentration, LCs could be generated in a form of viscous solution that is called LC-GO solution. Liu et al. used such viscous LC-GO solution along with the blade-coating technique to make a LC-GO film by a standard procedure. The viscous LC-GO film is directly attached to the substrate without using polymer binder, while the reduction of GO in water is also environmentally benign. The blade-rGO film achieved a specific capacitance of $250 \mathrm{~F} / \mathrm{g}$, significantly higher than the maximum capacitance of the spray-rGO film $(\sim 125 \mathrm{~F} / \mathrm{g})$. The higher specific capacitance of blade-rGO film suggests that large LCs assist positively with higher capacitance. On the one hand, water trapped in LC-GO domains helps to get rid of oxygen during the hydrothermal reduction process. More ions adsorption would happen under a higher degree of reduction in $\mathrm{rGO}$ sheets. On the other hand, the LC formation leads to a rumpled morphology of rGO sheets, preventing rGO sheets from restacking and increasing the specific surface area [65].

\subsubsection{Novel Design and Synthesis Methods}

In respect of innovative design, Ajayan et al. fabricated a novel type of ultrathin planar supercapacitors. This planar supercapacitor stands out with the following three advantages: (1) The electrolyte ions can get full access to all graphene sheets, thereby fully utilizing the high surface area 
provided by graphene; (2) More edges and basal plane surface area of the graphene are exposed in this structure; (3) This planar design reduces the thickness of the devices, such as single-layer graphene supercapacitors. This new type of graphene-based two-dimensional planar capacitor has a mass specific capacitance as $250 \mathrm{~F} / \mathrm{g}$, areal specific capacitance as $394 \mathrm{~F} / \mathrm{cm}^{2}$ [66].

Jang et al. fabricated mesoporous graphene nanoballs (MGBs) with large surface area and excellent conductivity through a CVD process on a basis of metal precursors as a catalyst. Polystyrene beads were functionalized with $-\mathrm{COOH}$ and $-\mathrm{SO}_{3} \mathrm{H}$ groups, which were subsequently coated with metal precursor. Such a hybrid offers 3D metal frames and correlates favorably with the graphene growth. MGB was immersed in $\mathrm{H}_{2} \mathrm{SO}_{4}$ solution to further improve the conductivity, which is a key factor in influencing the capacitance value. The $\mathrm{CV}$ displayed a relatively rectangular shape even at a high voltage scan rate, indicating EDL capacitance behavior without pseudocapacitance property. The MGB-based supercapacitor showed an excellent performance with a high specific capacitance as $206 \mathrm{~F} / \mathrm{g}$ and a slight decrease (4\%) in capacitance value after 10,000 cycles. The great performance of MGBs can be ascribed to the large accessible and effective surface area [67].

Besides the above two novel planar and nanoball catalyst designs, graphene nanoribbons (GNRs) appear as another novel form of graphene-based supercapacitor design. Given that GNR sheets also suffers from agglomeration and restacking due to Van der Waals force, it still remains quite a challenge to synthesize low stacking GNR sheets that is highly accessible to electrolyte. Singh et al. reported that novel lacey reduced graphene oxide nanoribbon (LRGONR) was synthesized (Figure 3) by chemically unzipping the multiwalled carbon nanotubes (MWCNTs) in the presence of strong oxidizing agent. The same set of oxidizers but with varied component portions continued to treat the opened MWCNTs for $8 \mathrm{~h}$ in order to maximize the defects in LRGONR. Extended oxidation created dispersion of defects/holes randomly in LRGONR, and thus increased the edge sites.

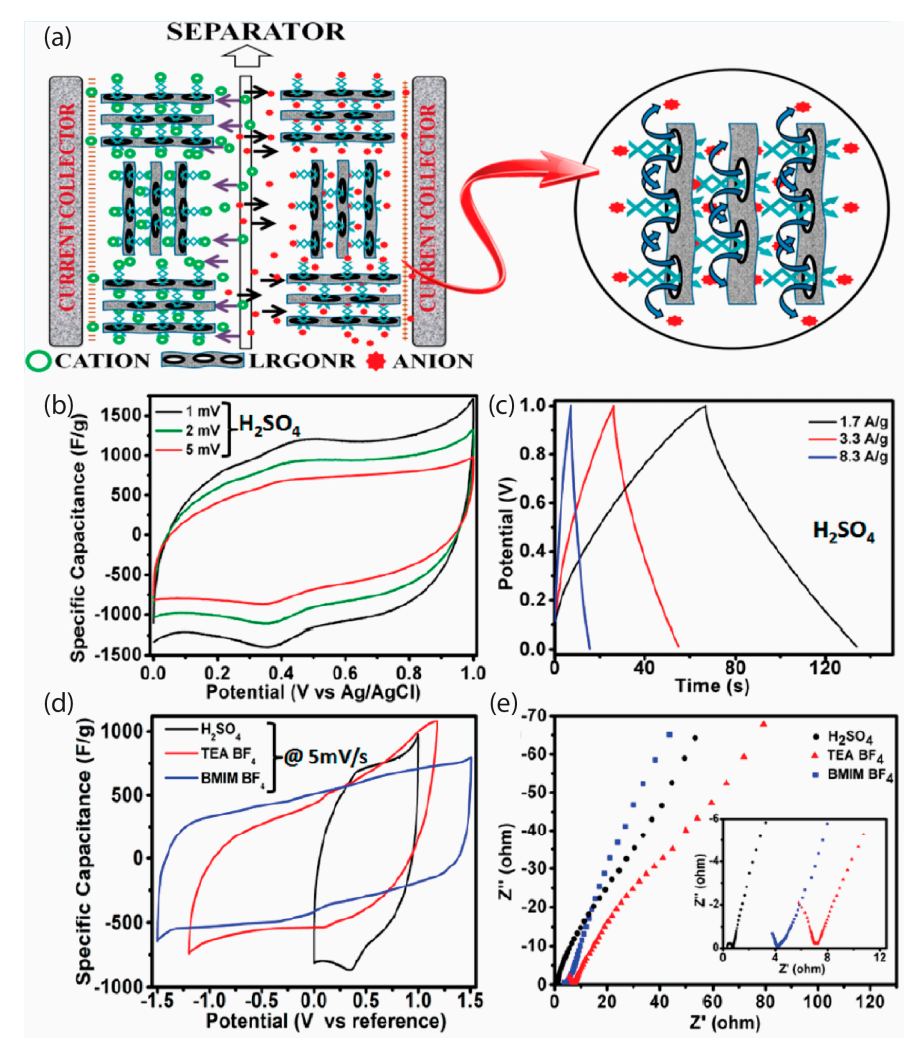

Figure 3. (a) The schematic drawing of a supercapacitor made of LRGONRs. (b) CV of LRGONR in $2 \mathrm{M} \mathrm{H}_{2} \mathrm{SO}_{4}$. (c) LRGONR galvanic charge-discharge. (d) Comparative CVs of LRGONR in $2 \mathrm{M} \mathrm{H}_{2} \mathrm{SO}_{4}$, 1.0 M TEA BF 4 , and 1.0 M BMIM BF 4 / AN. (e) Corresponding Nyquist plot of LRGONR (reprinted from reference [68] with permission from the American Chemical Society. Copyright 2015). 
The CV curve in Figure $3 \mathrm{~b}$ displayed a redox behavior characteristic of mixed EDL and pseudocapacitance, leading to a specific capacitance as $1042 \mathrm{~F} / \mathrm{g}$ at $1 \mathrm{mV} / \mathrm{s}$. This high value is ascribed to the contribution of both EDL capacitance from basal planes of individual LRGONR and the pseudocapacitance from associated surface groups at edge planes [68].

Heteroatom doping is an effective way to manipulate the electronic states of graphene-based materials and it worked with supercapacitor electrode material as well. Graphene-based materials with $\mathrm{N}$ or $\mathrm{B}$ doping have exhibited improved electrical properties as compared to undoped materials. The electronic states of electrode materials hold the key to determining capacitor performance. In Park et al.'s study, B-doped graphene nanoplatelets were synthesized by reduction of GO with the assistance of borane $\left(\mathrm{BH}_{3}\right)$-tetrahydrofuran (THF). In the $\mathrm{CV}$ testing, a two-electrode symmetrical supercapacitor cell was applied to show a specific capacitance value of $200 \mathrm{~F} / \mathrm{g}$, while the areal specific capacitance is even high up to $43 \mu \mathrm{F} / \mathrm{cm}^{2}$ at a low current density of $0.1 \mathrm{~A} / \mathrm{g}$. It has exceeded the capacitance limit that could be achieved purely from EDL with carbonaceous material.

In principle, B-doping functionalizing graphene networks with some hydroxyl and carboxylic acid groups enables the capacitance value to surpass EDL capacitance. Anodic and cathodic wide humps in the CVs provide an evidence for reversible faradaic reactions that result from both B- and/or $\mathrm{O}$-functional groups on the graphene surface. Under the synergistic effect of pseudocapacitance and EDL capacitance, capacitive response in CVs has been showed as a form of rectangular shape curves along with a pair of redox humps [69].

Besides the N- and B-doping, theoretic approach also reveals that the silicon $(\mathrm{Si})$ doping can significantly modulate the electronic state and improve the electrochemical properties of reduced graphene oxide (rGO). As shown in Figure 4c, the CV of Si-rGO exhibits no pronounced peak at various scan rates, and the rectangular shape suggests an ideal EDL capacitance behavior. The specific capacitance value of Si-rGO is $184.4 \mathrm{~F} / \mathrm{g}$, which is $48.5 \%$ superior to that of $\mathrm{rGO}(124.2 \mathrm{~F} / \mathrm{g})$ [70].

Microwave synthesis is an effective method to create new materials. It has better reaction kinetics, higher selectivity, and shorter reaction time. Mitlin et al. utilized microwave heating synthesis of CoPc to create 3D sponge-like graphene nanostructures that are capable of delivering an energy density of $7.1 \mathrm{Wh} / \mathrm{kg}$ at high power density of $48,000 \mathrm{~W} / \mathrm{kg}$. As a matter of fact, the whole synthesis process just spent less than $20 \mathrm{~min}$ [71].

\subsubsection{Tailorable and Flexible Device}

The popularization of wearable electronic and miniaturized devices requires that the supercapacitors should be shaped arbitrarily to meet a much more complicated integration in order to cater for utilization on different occasions. In this regard, tailorable supercapacitors that can be shaped or cut at the device level more flexibly need to be investigated. In addition, these tailorable supercapacitors could be applied for reliable power suppliers as well even if they are damaged. Yang et al. reported (Figure 4) a tailorable ultra-high-rate supercapacitor synthesized by electrochemically reduced graphene oxide (ErGO). Only through a one-step electrochemical deposition, the ErGO was evenly dispersed on nickel nanocone arrays. The material showed leading areal specific capacitance as $57.1 \mathrm{mF} / \mathrm{cm}^{2}$ at $2 \mathrm{mV} / \mathrm{s}$ and remarkable cycle stability (20,000 cycles with only $3.5 \%$ loss) [72].

In practice, mechanical deformation often destroys the reliability and stability of supercapacitors, so it is necessary to develop supercapacitors with a certain degree of stretchability and self-healability. Liu et al. fabricated rGO based fiber springs as electrodes for stretchable and self-healable supercapacitor. The diameter of fiber springs is so big enough that self-healable linking between broken electrode pieces could be observed. The stretchability and self-healability is realized by wrapping fiber springs with a self-healing polymer outer shell. The effect is outstanding. $82.4 \%$ capacitance is remained through a $100 \%$ stretch, while it still can remain $54.2 \%$ capacitance retention after the third healing [73]. 
(a)

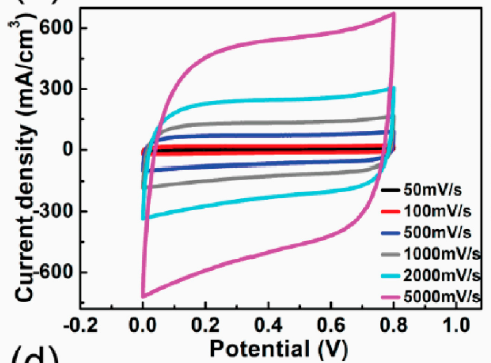

(d)

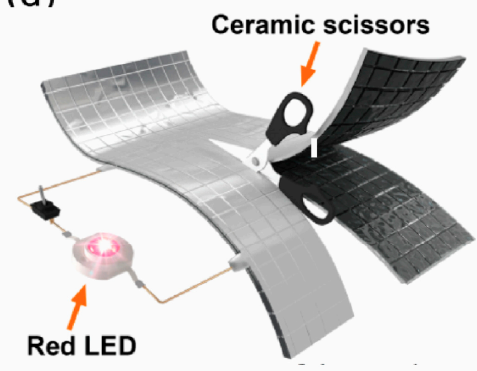

(b)

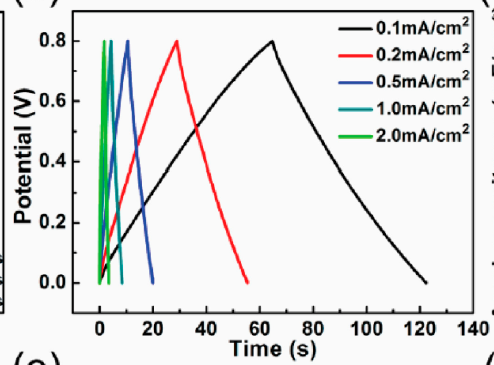

(e)

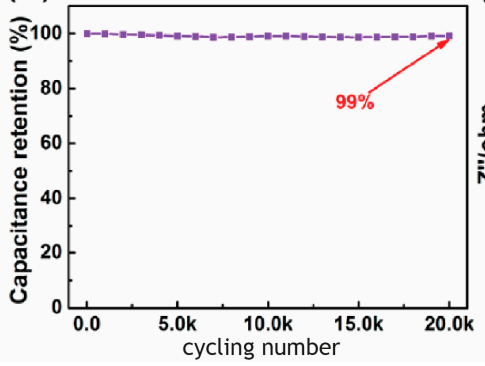

(c)

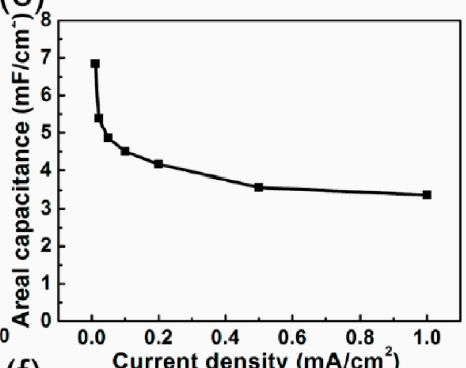

(f)

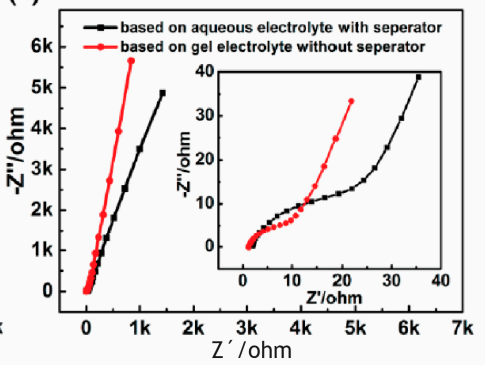

Figure 4. (a) CV curves of the TGS under different scan rates. (b) GCD curves of the TGS with various current density. (c) Schematic illustration of the shape-tailorable supercapacitor. (d) Areal and volumetric capacitances of the TGS with different current densities. (e) Capacitance retention for the TGS that has undergone 20,000 cycles. (f) Nyquist plots of the TGS without separator and the aqueous-electrolyte-based supercapacitor with a separator. The inset in $(\mathbf{f})$ is magnification of the high-frequency region (reprinted from reference [72] with permission from the American Chemical Society. Copyright 2015).

\subsection{Graphene-Based Pseudocapacitive Supercapacitor}

\subsection{1. $\mathrm{MnO}_{2} /$ Graphene Network}

Manganese dioxide $\left(\mathrm{MnO}_{2}\right)$ have been investigated intensively as a pseudocapacitive electrode material because of its high energy density and outstanding charge transfer ability based on rapid redox reactions on the electrode surface, leading to a much higher specific capacitance surpassing the limit of pure EDL charge storage. Additionally $\mathrm{MnO}_{2}$ has many favorable features including low price, environmental compatibility, sufficient resources, and ultra-high theoretical specific capacitance value. However, the $\mathrm{MnO}_{2}$ material still faces many disadvantages. The low specific surface area caused by the conventional co-precipitation method leads to a low specific capacitance value. In some cases the nanometer-sized $\mathrm{MnO}_{2}$ can provide large surface area and high specific capacitance, but during cycles of charge and discharge, the micro structure of $\mathrm{MnO}_{2}$ was deformed. Furthermore, the poor conductivity is another inevitable drawback of $\mathrm{MnO}_{2}$ when it comes to capacitance performance. Large-scale applications have a demand of high energy storage, the high loading of $\mathrm{MnO}_{2}$ materials which means an increase in electrode resistance. For these reasons, the feasible strategy is to combine the graphene material with high surface area and conductivity with $\mathrm{MnO}_{2}$ to improve its electrochemical performance.

In this regard, Bao et al. used 3D wrapping material such as CNTs or conducting polymer to wrap graphene $/ \mathrm{MnO}_{2}$. The function of the conducting wrapping material is two-fold. Firstly, it provides an additional electron transfer channel, not just relying on the graphene layer. Secondly, it can take part in the charge storage, because graphene and $\mathrm{MnO}_{2}$ got involved in the energy storage through EDL capacitance and pseudocapacitance, respectively. The specific wrapping structure with conductive CNTs or polymer renders a substantial rise in the specific capacitance by $\sim 20 \%$ and $\sim 45 \%$, respectively. The maximum specific capacitance value is as high as $\sim 380 \mathrm{~F} / \mathrm{g}$. As for the long-term cycle stability, this 
ternary hybrid displayed a $>95 \%$ capacitance retention after 3000 sweepings [74]. To supplement $\mathrm{MnO}_{2}$ related pseudocapacitance observation, Norouzi et al. investigated the electrochemical properties of $\mathrm{N}-\mathrm{rGO} / \mathrm{MnO}_{2}$ nanostructure. The $\mathrm{CV}$ curves of the $\mathrm{N}-\mathrm{rGO} / \mathrm{MnO}_{2}$ exhibited a quasi-rectangular shape and symmetric I-V responses, which proved the ideal pseudocapacitive behavior of the materials. The specific capacitance for the $\mathrm{N}-\mathrm{rGO} / \mathrm{MnO}_{2}$ electrodes is $453 \mathrm{~F} / \mathrm{g}$ [75].

Wu et al. further fabricated a highly porous ternary hybrid spheres consisting of $\mathrm{Ni}(\mathrm{OH})_{2}, \mathrm{MnO}_{2}$ and $\mathrm{rGO}$ via a hydrothermal codeposition pathway. The hierarchical spherical structure results from a series of individual steps including primary particle formation, primary particle aggregation into chains, subsequent crystallization, and nanosheet formation. The $\mathrm{Ni}(\mathrm{OH})_{2}-\mathrm{MnO}_{2}-\mathrm{rGO}$ nanosheets tend to self-assemble into a spherical shape. This ternary hybrid exhibited an outstanding specific capacitance of $1985 \mathrm{~F} / \mathrm{g}$ at $2 \mathrm{~A} / \mathrm{g}$ and energy density of $54.0 \mathrm{Wh} / \mathrm{kg}$ [76].

The concept of flexible supercapacitor can also be achieved in graphene-based pseudosupercapacitor. Xie et al. have designed a freestanding flexible 3D graphene $/ \mathrm{MnO}_{2}$ composite network as electrode material for supercapacitors. The freestanding, lightweight 3D graphene networks showed excellent mechanical properties, which allows it to be an ideal support for $\mathrm{MnO}_{2}$ and permit a mass loading high up to $9.8 \mathrm{mg} / \mathrm{cm}^{2}$, resulting in a high areal specific capacitance as $1.42 \mathrm{~F} / \mathrm{cm}^{2}$. The outstanding electrochemical performance including high specific capacitance and long term cycling stability can be attributed to the following reasons: (1) Electron transfer and electrolyte ions easy access to electrode surfaces can be guaranteed by the high conductivity and porous structure of 3D graphene networks; (2) Electrochemical deposition induces a tight contact between the graphene and $\mathrm{MnO}_{2}$ nanomaterials which reduces the contact resistance and keeps adhesion stable. That's why it can tolerate a certain degree of deformation; (3) The high specific surface area of the 3D graphene networks ensures a dispersive distribution of $\mathrm{MnO}_{2}$ among graphene nanopores, which leads to a large active surface area and full accessibility for the electrolyte to the $\mathrm{MnO}_{2}$ [77].

\subsubsection{Other Metal Oxide/Graphene Network}

Among transition metal oxide candidates, $\mathrm{Co}_{3} \mathrm{O}_{4}$ possesses some intrinsic properties that enable it to be an ideal supercapacitive material, such as high theoretical specific capacitance value $(3560 \mathrm{~F} / \mathrm{g})$, environmental friendliness, and good electrochemical performance. However, the large-scale application is hindered by the observed low specific capacitances in practice and low electronic conductivity of $\mathrm{Co}_{3} \mathrm{O}_{4}$. Graphene nanosheets (GNSs) are an excellent support to host $\mathrm{Co}_{3} \mathrm{O}_{4}$, because of their outstanding feature of high conductivity and specific surface. Even though GNSs have its intrinsic drawback of restacking because of $\pi-\pi$ interactions and the van der Waals force, it could be solved by employing a vertically aligned graphene nanosheet (VAGN) with its bottom fixed to the surface of the substrate, maintaining the space between graphene nanosheets. Furthermore, more space in the GNS makes the internal resistance lower and electrolyte is easier to reach the inner part of electrode. Wang et al. used $\mathrm{Co}_{3} \mathrm{O}_{4} \mathrm{NPs}$ deposited on the VAGN to make a novel supercapacitor (Figure 5). The VAGN is used for the backbone working with carbon fabric. In electrochemical performance testing, $\mathrm{Co}_{3} \mathrm{O}_{4}$ achieved a high specific capacitance of up to $3482 \mathrm{~F} / \mathrm{g}$ as well as the highest energy density up to $80 \mathrm{Wh} / \mathrm{kg}$. The highest power density was also recorded up to $20 \mathrm{~kW} / \mathrm{kg}$. Even though the device was bent to $150^{\circ}$, it still showed a good electrochemical performance with excellent flexibility. $86.3 \%$ of the capacitance retention was recorded when 20,000 cycles at $20 \mathrm{~A} / \mathrm{g}$ are done [78]. 

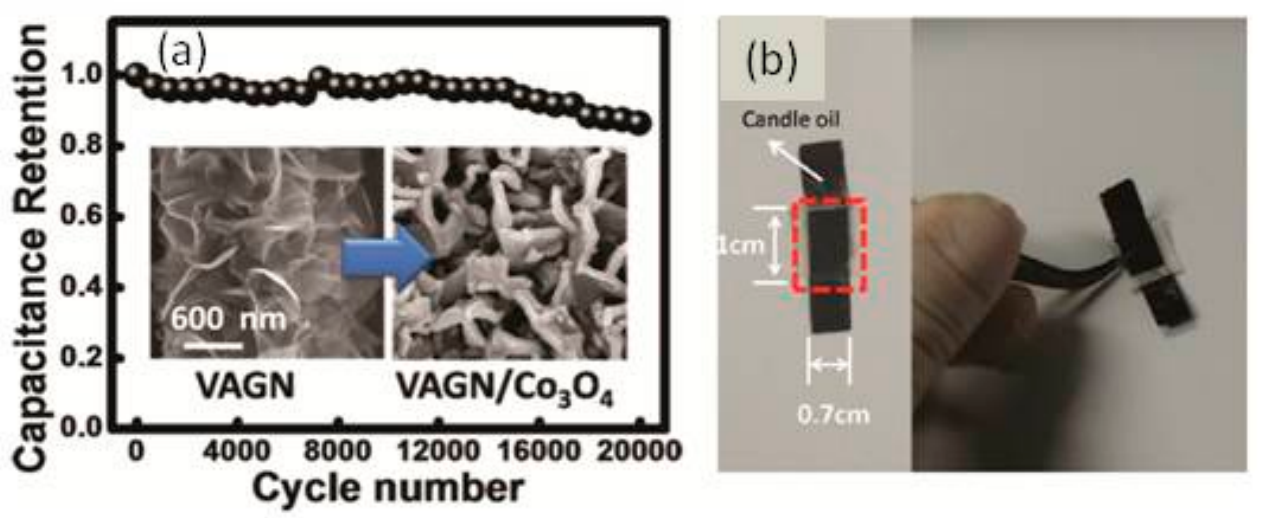

Figure 5. (a) High-resolution SEM images of the VAGN and VAGN/ $\mathrm{Co}_{3} \mathrm{O}_{4}$. (b) Optical photographs of the fabricated solide-state supercapacitor device (reprinted from reference [78] with permission from the American Chemical Society. Copyright 2015).

Ceria $\left(\mathrm{CeO}_{2}\right)$ has been considered as one of the active redox materials for supercapacitors due to its low price, abundant reserves, and particularly outstanding redox features. The $\mathrm{CeO}_{2} / \mathrm{N}-\mathrm{rGO}$ nanocomposite was prepared through a sonochemical method. The $\mathrm{CV}$ curve of the $\mathrm{CeO}_{2} / \mathrm{N}-\mathrm{rGO}$ displayed a non-rectangular shape of faradaic redox peaks from -0.2 to $0.5 \mathrm{~V}$ in potential scale, indicating an obvious pseudocapacitative behavior. Compared with individual $\mathrm{N}-\mathrm{rGO}$ and $\mathrm{CeO}_{2}$, the synergistic effect of $\mathrm{N}-\mathrm{rGO}$ and $\mathrm{CeO}_{2}$ is reflected in the form of larger area enclosed by the CV curve [79].

Decorating hematite $\left(\alpha-\mathrm{Fe}_{2} \mathrm{O}_{3}\right)$ with a conductive material such as graphene is an effective method to enhance its electrochemical properties. Furthermore, $\mathrm{Fe}_{2} \mathrm{O}_{3}$ on graphene can minimize the aggregation or restacking of graphene. Li et al. reported a specific capacitance of $240 \mathrm{~F} / \mathrm{g}$ at $1 \mathrm{~A} / \mathrm{g}$ for solvothermal synthesis of $\mathrm{Fe}_{2} \mathrm{O}_{3}$ loaded activated carbon materials [83]. Cheng et al. prepared a $\alpha-\mathrm{Fe}_{2} \mathrm{O}_{3} / \mathrm{rGO}$ nanocomposite. The ion transport is favorably based on the conductive $2 \mathrm{D}$ nanoplate-shaped structure. Besides, $2 \mathrm{D}$ structure is effective to make full use of the active materials. The final product showed a high special capacitance of $903 \mathrm{~F} / \mathrm{g}$ at a current density of $1 \mathrm{~A} / \mathrm{g}$. It has exceeded most of other reported $\alpha-\mathrm{Fe}_{2} \mathrm{O}_{3}$ nanostructures before [80].

\subsection{Graphene-Based Hybrid Supercapacitors}

HSs, with a supercapacitor-battery hybrid system, are electrochemical energy storage devices that integrate the advantages of high power density from a supercapacitor and high energy density from a LIB. In most cases, a HS is composed of a LIB-type anode and an EDLC-type cathode in organic electrolytes. By combining two types of electrodes in one HS system, the electrochemical performance is improved in both the power and energy densities, which stem from the fast charging/discharging rate of the cathode and the high specific capacity of the anode. Last but not least, the organic electrolytes can provide a much wider working voltage window. However, for most reported HS so far, due to the imbalance of charge-storage capacity and electrode kinetics between capacitor-type cathode and battery-type anode, both appropriate electrodes materials are not coupled. In addition, the rate capability and the long-term stability are still challenging. Conventionally for capacitor-type electrodes (cathode), the conductivity and specific surface area of most commonly used activated carbon (AC) is relatively low; for battery-type electrodes (anode) the conductivity and Li-diffusivity of $\mathrm{Li}_{4} \mathrm{Ti}_{5} \mathrm{O}_{12}$ (LTO), metal oxides and graphite are sluggish. Graphene, with its extraordinary properties, has emerged as an outstanding electrochemical active material individually or appealing conductive carbon matrices for nanostructure hybrid electrodes in electrochemical energy storage devices. Thus, with rational design, the graphene-based material exhibited greatly improved electrochemical performance as cathode or anode material for HSs. 


\subsubsection{As Cathode Materials}

Due to the high theoretical specific surface area and capacitance, graphene offers great potential to ultimately replace the conventional AC in EDLCs. Aravindan et al. reported a trigol-reduced graphene oxide (TRGO) cathode material with a reversible capacity of ca. $58 \mathrm{mAh} / \mathrm{g}$, which is about twice as high as commercial AC cathode. When employing LTO as anode material, the LTO/ /TRGO HSs delivered maximum energy, power densities and cycle ability of ca. $45 \mathrm{Wh} / \mathrm{kg}, 3.3 \mathrm{~kW} / \mathrm{kg}$ and 5000 cycles, respectively [84].

The application of porous $3 \mathrm{D}$ graphene network has been demonstrated to be an effective way to improve the electronic performance of graphene containing composites. For example, 3D porous graphene sucrose (G-SU) is another excellent material for cathode electrode in HS. When employing the $\mathrm{Fe}_{3} \mathrm{O}_{4}$ /graphene $\left(\mathrm{Fe}_{3} \mathrm{O}_{4} / \mathrm{G}\right)$ as the anode material, the $\mathrm{Fe}_{3} \mathrm{O}_{4} / \mathrm{G} / / \mathrm{G}-\mathrm{SU}$ demonstrated an ultrahigh energy density of $147 \mathrm{Wh} / \mathrm{kg}$ [85]. Wang et al. employed the 3D porous graphene hydrogels as the cathode and $\mathrm{TiO}_{2}$ nanobelt arrays grown directly on Ti foil as the anode. The energy density of such prepared $\mathrm{HS}$ can be high up to $82 \mathrm{Wh} / \mathrm{kg}$ at $570 \mathrm{~W} / \mathrm{kg}$. Especially at an extremely fast $(8.4 \mathrm{~s})$ charge/discharge rate, the HS delivered an energy density of $21 \mathrm{Wh} / \mathrm{kg}$ [86]. LiMnPO $(\mathrm{LMP}$ ) suffers from inferior ionic diffusivity and electroconductivity. To solve this problem, the 3D rGO aerogel supporting LMP NPs was synthesized by solvothermal treatment and subsequent a restacking process. The introduction of rGO significantly improves the electronic conductivity, as well as enlarges the electrode/electrolyte interface area and increases electrochemical properties of LMP/rGO composites. The HS assembled as $\mathrm{rGO} / / \mathrm{LMP} / \mathrm{rGO}$ achieved a specific energy density of $16.46 \mathrm{Wh} / \mathrm{kg}$ at the power density of $0.38 \mathrm{~kW} / \mathrm{kg}$, and retained $91.2 \%$ of the initial capacity after 10,000 cycles at a current density of $2 \mathrm{~A} / \mathrm{g}$ [87].

\subsubsection{As Anode Material}

Graphene can act as the anode material for LIBs individually due to its high theoretical lithium storage capacity of $744 \mathrm{mAh} / \mathrm{g}$ assuming Li ions are attached to both sides of the graphene. Ragupathy et al. reported the HS comprising nitrogen-doped graphene (NDG) and electrospunderived $\mathrm{LiNi}_{0.5} \mathrm{Mn}_{1.5} \mathrm{O}_{4}$ as anode and cathode, respectively. The NDG/ $/ \mathrm{LiNi}_{0.5} \mathrm{Mn}_{1.5} \mathrm{O}_{4}$ demonstrated a maximum energy density of $15 \mathrm{Wh} / \mathrm{kg}$ at a power density of $110 \mathrm{~W} / \mathrm{kg}$ [88].

Most of the conventionally utilized anode materials suffer from the poor electrical conductivity and low lithium ion diffusivity. Graphene can act as a substrate for nanostructured anode materials, so as to increase the specific area and provide shorter ion diffusion pathway. Lai et al. synthesized a free-standing LTO/graphene foam (GF) compound via a hydrothermal process. Owing to the synergistic effect of the nanostructured LTO and the GF with a hierarchical structure and high electrical conductivity, the HSs based on the LTO/GF anode and AC cathode achieved energy density values of 46 , and $26 \mathrm{Wh} / \mathrm{kg}$ at power densities of 625 , and $2500 \mathrm{~W} / \mathrm{kg}$, respectively [89]. With its large pseudocapacitive Li-ion intercalation capacity, orthorhombic $\mathrm{Nb}_{2} \mathrm{O}_{5}$ is a good anode material in HSs. Huo et al. synthesized anode material consisting of long $\mathrm{Nb}_{2} \mathrm{O}_{5}$ nanowires and graphene $\left(\mathrm{L}-\mathrm{Nb}_{2} \mathrm{O}_{5} \mathrm{NWs} / \mathrm{rGO}\right)$. The hybrid electrode showed a high reversible specific capacity of $160 \mathrm{mAh} / \mathrm{g}$ at a current density of $0.2 \mathrm{~A} / \mathrm{g}$, superior rate capability and excellent cycle stability. The HSs device with $\mathrm{L}-\mathrm{Nb}_{2} \mathrm{O}_{5} / \mathrm{rGO}$ as anodes and biomass-derived carbon nanosheets as cathodes delivered energy density values of 106 , and $32 \mathrm{Wh} / \mathrm{kg}$ at power densities of 0.58 , and $14 \mathrm{~kW} / \mathrm{kg}$, respectively. In addition, the HSs device demonstrated little capacitance decay after 1000 cycles [90]. Molybdenum disulfide $\left(\mathrm{MoS}_{2}\right)$ is a promising anode material for lithium-ion batteries based on its high theoretical specific capacity, layered structure facilitating $\mathrm{Li}$ intercalation/deintercalation, and a wide lithiation potential. Lee et al. incorporated $\mathrm{MoS}_{2}$ flocculent onto 3D GF (MoS $@ 3$ DGF) via a simple solution-based process. When employed as the anode for HSs, $\mathrm{MoS}_{2} @ 3$ DGF exhibited a high energy density of $156 \mathrm{Wh} / \mathrm{kg}$ at $197 \mathrm{~W} / \mathrm{kg}$, and remained an energy density of $97 \mathrm{Wh} / \mathrm{kg}$ at a large power density of $8314 \mathrm{~W} / \mathrm{kg}$ [91]. 


\section{Conclusions}

In summary, the many cases shown in this review demonstrate the crucial role that graphene plays in the field of electrocatalysts for ORR and electrode materials for supercapacitors. In the first role, graphene not only acts as a good support for other active catalysts but also possesses electrocatalytic activity for ORR itself. Graphene-based materials can induce favourable catalyst-support interactions to provide stability and activity enhancements. In addition, graphene itself and its different morphologies or forms including nanosheets, nanoribbons, quantum dots, doped with heteroatoms or modified with functional groups display pronounced electrocatalytic capability. In the latter aspect, the characteristics of graphene-based composites are utilized in many respects to provide a porous 3D structure, formulate novel supercapacitors with innovative designs, and construct flexible and tailorable devices. Furthermore, many materials hybridized with graphene present an outstanding pseudocapacitance behavior. Graphene is an effective electrochemical material, which can work as both cathodes and anodes in HSs.

Acknowledgments: All sources of funding of the study should be disclosed. Please clearly indicate grants that you have received in support of your research work. Clearly state if you received funds for covering the costs to publish in open access.

Author Contributions: Peipei Huo made her contribution to literature search, study design, and writing of the whole article. Bo Liu and Mingdong Dong made their contributions to study design and editing of writing of the whole article. Peng Zhao made his contribution to literature search and writing of Section 2 mainly. Yin Wang and Guangchao Yin made their contributions to literature search of Section 3 mainly.

Conflicts of Interest: The authors declare no conflict of interest. The founding sponsors had no role in the design of the study; in the collection, analyses, or interpretation of data; in the writing of the manuscript, and in the decision to publish the results.

\section{References}

1. Aricò, A.S.; Bruce, P.; Scrosati, B.; Tarascon, J.M.; Schalkwijk, W.V. Nanostructured materials for advanced energy conversion and storage devices. Nat. Mater. 2005, 4, 366-377. [CrossRef] [PubMed]

2. Winter, M.; Brodd, R.J. What are batteries, fuel cells, and supercapacitors? Chem. Rev. 2004, 104, 4245-4269. [CrossRef] [PubMed]

3. Tibaquirá, J.E.; Hristovski, K.D.; Westerhoff, P.; Posner, J.D. Recovery and quality of water produced by commercial fuel cells. Int. J. Hydrogen Energy 2011, 36, 4022-4028. [CrossRef]

4. Ding, R.; Li, X.D.; Shi, W.; Xu, Q.L.; Liu, E.H. One-pot solvothermal synthesis of ternary Ni-Co-P micro/nano-structured materials for high performance aqueous asymmetric supercapacitors. Chem. Eng. J. 2017, 320, 376-388. [CrossRef]

5. Thakur, A.K.; Choudhary, R.B.; Majumder, M.; Majhi, M. Fairly improved pseudocapacitance of $\mathrm{PTP} / \mathrm{PANI} / \mathrm{TiO}_{2}$ nanohybrid composite electrode material for supercapacitor applications. Ionics 2017, 42, 1-12. [CrossRef]

6. Kim, S.; Kim, J.H.; Oh, J.G.; Jang, K.L.; Jeong, B.H.; Hong, B.K.; Kim, T.S. Mechanical behavior of free-standing fuel cell electrodes on water surface. ACS Appl. Mater. Interfaces 2016, 8, 15391-15398. [CrossRef] [PubMed]

7. Filanovsky, B.; Granot, E.; Dirawi, R.; Presman, I.; Kuras, I.; Patolsky, F. Nanotextured metal copper substrates as powerful and long-lasting fuel cell anodes. Nano Lett. 2011, 11, 1727-1732. [CrossRef] [PubMed]

8. Dru, D.; Baranton, S.; Bigarré, J.; Buvat, P.; Coutanceau, C. Fluorine-free Pt nanocomposites for three-phase interfaces in fuel cell electrodes. ACS Catal. 2016, 6, 6993-7001. [CrossRef]

9. Unni, S.M.; Illathvalappil, R.; Bhange, S.N.; Puthenpediakkal, H.; Kurungot, S. Carbon Nanohorn-derived graphene nanotubes as a platinum-free fuel cell cathode. ACS Appl. Mater. Interfaces 2015, 7, 24256-24264. [CrossRef] [PubMed]

10. Dombrovskis, J.K.; Jeong, H.Y.; Fossum, K.; Terasaki, O.; Palmqvist, A.E.C. Transition metal ion-chelating ordered mesoporous carbons as noble metal-free fuel cell catalysts. Chem. Mater. 2013, 25, 856-861. [CrossRef]

11. Singh, D.; Mamtani, K.; Bruening, C.R.; Miller, J.T.; Ozkan, U.S. Use of $\mathrm{H}_{2} \mathrm{~S}$ to probe the active sites in FeNC catalysts for the oxygen reduction reaction (ORR) in acidic media. ACS Catal. 2014, 4, 3454-3462. [CrossRef] 
12. Roche, I.; Chaînet, E.; Chatenet, M.; Vondrák, J. Carbon-supported manganese oxide nanoparticles as electrocatalysts for the oxygen reduction reaction (ORR) in alkaline medium: Physical characterizations and ORR mechanism. J. Phys. Chem. C 2007, 111, 1434-1443. [CrossRef]

13. Asara, G.G.; Paz-Borbón, L.O.; Baletto, F. “Get in touch and keep in contact": Interface effect on the oxygen reduction reaction (ORR) activity for supported PtNi nanoparticles. ACS Catal. 2016, 6, 4388-4393. [CrossRef]

14. Khan, I.A.; Qian, Y.H.; Badshah, A.; Nadeem, M.A.; Zhao, D. Highly porous carbon derived from MOF-5 as a support of ORR electrocatalysts for fuel cells. ACS Appl. Mater. Interfaces 2016, 8, 17268-17275. [CrossRef] [PubMed]

15. Peng, H.L.; Liu, F.F.; Liu, X.J.; Liao, S.J.; You, C.H.; Tian, X.L.; Nan, H.X.; Luo, F.; Song, H.Y.; Fu, Z.Y.; et al. Effect of transition metals on the structure and performance of the doped carbon catalysts derived from polyaniline and melamine for ORR application. ACS Catal. 2014, 4, 3797-3805. [CrossRef]

16. Yang, M.; Liu, Y.J.; Chen, H.B.; Yang, D.G.; Li, H.M. Porous N-doped carbon prepared from triazine-based polypyrrole network: A highly efficient metal-free catalyst for oxygen reduction reaction in alkaline electrolytes. ACS Appl. Mater. Interfaces 2016, 8, 28615-28623. [CrossRef] [PubMed]

17. Bo, X.J.; Han, C.; Zhang, Y.F.; Guo, L.P. Confined nanospace synthesis of less aggregated and porous nitrogen-doped graphene as metal-free electrocatalysts for oxygen reduction reaction in alkaline solution. ACS Appl. Mater. Interfaces 2014, 6, 3023-3030. [CrossRef] [PubMed]

18. Zhang, K.; Yue, Q.L.; Chen, G.F.; Zhai, Y.L.; Wang, L.; Wang, H.S.; Zhao, J.S.; Liu, J.F.; Jia, J.B.; Li, H.B. Effects of acid treatment of Pt-Ni alloy nanoparticles@graphene on the kinetics of the oxygen reduction reaction in acidic and alkaline solutions. J. Phys. Chem. C 2011, 115, 379-389. [CrossRef]

19. He, Q.G.; Li, Q.; Khene, S.; Ren, X.M.; López-Suárez, F.E.; Lozano-Castelló, D.; Bueno-López, A.; $\mathrm{Wu}, \mathrm{G}$. High-loading cobalt oxide coupled with nitrogen-doped graphene for oxygen reduction in anion-exchange-membrane alkaline fuel cells. J. Phys. Chem. C 2013, 117, 8697-8707. [CrossRef]

20. Kumar, K.; Canaff, C.; Rousseau, J.; Arrii-Clacens, S.; Napporn, T.W.; Habrioux, A.; Kokoh, K.B. Effect of the oxide-carbon heterointerface on the activity of $\mathrm{Co}_{3} \mathrm{O}_{4} / \mathrm{NRGO}$ nanocomposites toward ORR and OER. J. Phys. Chem. C 2016, 120, 7949-7958. [CrossRef]

21. Deming, C.P.; Mercado, R.; Gadiraju, V.; Sweeney, S.W.; Khan, M.; Chen, S.W. Graphene quantum dots-supported palladium nanoparticles for Efficient electrocatalytic reduction of oxygen in alkaline media. ACS Sustain. Chem. Eng. 2015, 3, 3315-3323. [CrossRef]

22. Vinoth, R.; Patil, I.M.; Pandikumar, A.; Kakade, B.A.; Huang, N.M.; Dionysios, D.D.; Neppolian, B. Synergistically enhanced electrocatalytic performance of an N-doped graphene quantum dot-decorated 3D $\mathrm{MoS}_{2}$-graphene nanohybrid for oxygen reduction reaction. ACS Omega 2016, 1, 971-980. [CrossRef]

23. Yin, H.J.; Tang, H.J.; Wang, D.; Gao, Y.; Tang, Z.Y. Facile synthesis of surfactant-free Au cluster/graphene hybrids for high-performance oxygen reduction reaction. ACS Nano 2012, 6, 8288-8297. [CrossRef] [PubMed]

24. Cai, J.; Niu, H.T.; Li, Z.Y.; Du, Y.; Cizek, P.; Xie, Z.L.; Xiong, H.G.; Lin, T. High-performance supercapacitor electrode materials from cellulose-derived carbon nanofibers. ACS Appl. Mater. Interfaces 2015, 7, 14946-14953. [CrossRef] [PubMed]

25. Li, P.X.; Yang, Y.B.; Shi, E.Z.; Shen, Q.C.; Shang, Y.Y.; Wu, S.T.; Wei, J.Q.; Wang, K.L.; Zhu, H.W.; Yuan, Q.; et al. Core-double-shell, carbon nanotube@polypyrrole@ $\mathrm{MnO}_{2}$ sponge as freestanding, compressible supercapacitor electrode. ACS Appl. Mater. Interfaces 2014, 6, 5228-5234. [CrossRef] [PubMed]

26. Ji, J.Y.; Zhang, L.L.; Ji, H.X.; Li, Y.; Zhao, X.; Bai, X.; Fan, X.B.; Zhang, F.B.; Ruoff, R.S. Nanoporous Ni(OH $)_{2}$ thin film on 3D ultrathin-graphite foam for asymmetric supercapacitor. ACS Nano 2013, 7, 6237-6243. [CrossRef] [PubMed]

27. Hahm, M.G.; Reddy, A.L.M.; Cole, D.P.; Rivera, M.; Vento, J.A.; Nam, J.; Jung, H.Y.; Kim, Y.L.; Narayanan, N.T.; Hashim, D.P.; et al. Carbon nanotube-nanocup hybrid structures for high power supercapacitor applications. Nano Lett. 2012, 12, 5616-5621. [CrossRef] [PubMed]

28. Vijayakumar, S.; Nagamuthu, S.; Muralidharan, G. Supercapacitor studies on $\mathrm{NiO}$ nanoflakes synthesized through a microwave route. ACS Appl. Mater. Interfaces 2013, 5, 2188-2196. [CrossRef] [PubMed]

29. Shi, P.P.; Li, L.; Hua, L.; Qian, Q.Q.; Wang, P.F.; Zhou, J.Y.; Sun, G.Z.; Huang, W. Design of amorphous manganese oxide@multiwalled carbon nanotube fiber for robust solid-state supercapacitor. ACS Nano 2017, 11, 444-452. [CrossRef] [PubMed] 
30. Kim, J.S.; Shin, S.S.; Han, H.S.; Oh, L.S.; Kim, D.H.; Kim, J.H.; Hong, K.S.; Kim, J.Y. 1-D structured flexible supercapacitor electrodes with prominent electronic/ionic transport capabilities. ACS Appl. Mater. Interfaces 2014, 6, 268-274. [CrossRef] [PubMed]

31. Choudhary, N.; Li, C.; Chung, H.S.; Moore, J.; Thomas, J.; Jung, Y. High-performance one-body core/shell nanowire supercapacitor enabled by conformal growth of capacitive 2D WS 2 layers. ACS Nano 2016, 10, 10726-10735. [CrossRef] [PubMed]

32. Tan, Y.M.; Xu, C.F.; Chen, G.X.; Liu, Z.H.; Ma, M.; Xie, Q.J.; Zheng, N.F.; Yao, S.Z. Synthesis of ultrathin nitrogen-doped graphitic carbon nanocages as advanced electrode materials for supercapacitor. ACS Appl. Mater. Interfaces 2013, 5, 2241-2248. [CrossRef] [PubMed]

33. Tang, D.H.; Hu, S.; Dai, F.; Yi, R.; Gordin, M.L.; Chen, S.R.; Song, J.X.; Wang, D.H. Self-templated synthesis of mesoporous carbon from carbon tetrachloride precursor for supercapacitor electrodes. ACS Appl. Mater. Interfaces 2016, 8, 6779-6783. [CrossRef] [PubMed]

34. Zhang, Y.; Zou, Q.H.; Hsu, H.S.; Raina, S.; Xu, Y.X.; Kang, J.B.; Chen, J.; Deng, S.Z.; Xu, N.S.; Kang, W.P. Morphology effect of vertical graphene on the high performance of supercapacitor electrode. ACS Appl. Mater. Interfaces 2016, 8, 7363-7369. [CrossRef] [PubMed]

35. Singh, A.K.; Sarkar, D.; Karmakar, K.; Mandal, K.; Khan, G.G. High-performance supercapacitor electrode based on cobalt oxide-manganese dioxide-nickel oxide ternary 1D hybrid nanotubes. ACS Appl. Mater. Interfaces 2016, 8, 20786-20792. [CrossRef] [PubMed]

36. Liu, Y.Z.; Li, G.R.; Guo, Y.; Ying, Y.L.; Peng, X.S. Flexible and binder-free hierarchical porous carbon film for supercapacitor electrodes derived from MOFs/CNT. ACS Appl. Mater. Interfaces 2017, 9, 14043-14050. [CrossRef] [PubMed]

37. Wei, X.J.; Wan, S.G.; Jiang, X.Q.; Wang, Z.; Gao, S.Y. Peanut-shell-like porous carbon from nitrogen-containing poly-N-phenylethanolamine for high-performance supercapacitor. ACS Appl. Mater. Interfaces 2015, 7, 22238-22245. [CrossRef] [PubMed]

38. Bai, M.H.; Bian, L.J.; Song, Y.; Liu, X.X. Electrochemical codeposition of vanadium oxide and polypyrrole for high-performance supercapacitor with high working voltage. ACS Appl. Mater. Interfaces 2014, 6, 12656-12664. [CrossRef] [PubMed]

39. Khan, M.; Tahir, M.N.; Adil, S.F.; Khan, H.U.; Siddiqui, M.R.H.; Al-warthan, A.A.; Tremel, W. Graphene based metal and metal oxide nanocomposites: Synthesis, properties and their applications. J. Mater. Chem. A 2015, 3, 18753-18808. [CrossRef]

40. Kou, R.; Shao, Y.Y.; Wang, D.H.; Engelhard, M.H.; Kwak, J.H.; Wang, J.; Viswanathan, V.V.; Wang, C.M.; Lin, Y.H.; Wang, Y.; et al. Enhanced activity and stability of Pt catalysts on functionalized graphene sheets for electrocatalytic oxygen reduction. Electrochem. Commun. 2009, 11, 954-957. [CrossRef]

41. Lu, T.; Zhang, Y.P.; Li, H.B.; Pan, L.K.; Li, Y.L.; Sun, Z. Electrochemical behaviors of graphene-ZnO and graphene-SnO $\mathrm{Sn}_{2}$ composite films for supercapacitors. Electrochi. Acta 2010, 55, 4170-4173. [CrossRef]

42. Sakthinathan, S.; Kubendhiran, S.; Chen, S.M.; Karuppiah, C.; Chiu, T.W. Novel bifunctional electrocatalyst for ORR activity and methyl parathion detection based on reduced graphene oxide/palladium tetraphenylporphyrin nanocomposite. J. Phys. Chem. C 2017, 121, 14096-14107. [CrossRef]

43. Guo, S.J.; Sun, S.H. FePt nanoparticles assembled on graphene as enhanced catalyst for oxygen reduction reaction. J. Am. Chem. Soc. 2012, 134, 2492-2495. [CrossRef] [PubMed]

44. Wu, Z.S.; Yang, S.B.; Sun, Y.; Parvez, K.; Feng, X.L.; Müllen, K. 3D nitrogen-doped graphene aerogel-supported $\mathrm{Fe}_{3} \mathrm{O}_{4}$ nanoparticles as efficient electrocatalysts for the oxygen reduction reaction. J. Am. Chem. Soc. 2012, 134, 9082-9085. [CrossRef] [PubMed]

45. Liang, Y.Y.; Wang, H.L.; Zhou, J.G.; Li, Y.G.; Wang, J.; Regier, T.; Dai, H.J. Covalent hybrid of spinel manganese-cobalt oxide and graphene as advanced oxygen reduction electrocatalyst. J. Am. Chem. Soc. 2012, 134, 3517-3523. [CrossRef] [PubMed]

46. Gartia, Y.; Parnell, C.M.; Watanabe, F.; Szwedo, P.; Biris, A.S.; Peddi, N.; Nima, Z.A.; Ghosh, A. Graphene-enhanced oxygen reduction by $\mathrm{MN}_{4}$ type cobalt(III) catalyst. ACS Sustain. Chem. Eng. 2015, 3, 97-102. [CrossRef]

47. Jahan, M.; Bao, Q.L.; Loh, K.P. Electrocatalytically active graphene-porphyrin MOF composite for oxygen reduction reaction. J. Am. Chem. Soc. 2012, 134, 6707-6713. [CrossRef] [PubMed]

48. Qu, L.T.; Liu, Y.; Baek, J.B.; Dai, L.M. Nitrogen-doped graphene as efficient metal-free electrocatalyst for oxygen reduction in fuel cells. ACS Nano 2010, 4, 1321-1326. [CrossRef] [PubMed] 
49. Wang, S.Y.; Yu, D.S.; Dai, L.M.; Chang, D.W.; Baek, J.B. Polyelectrolyte-functionalized graphene as metal-free electrocatalysts for oxygen reduction. ACS Nano 2011, 5, 6202-6209. [CrossRef] [PubMed]

50. Liao, Y.L.; Gao, Y.; Zhu, S.M.; Zheng, J.S.; Chen, Z.X.; Yin, C.; Lou, X.H.; Zhang, D. Facile fabrication of $\mathrm{N}$-doped graphene as efficient electrocatalyst for oxygen reduction reaction. ACS Appl. Mater. Interfaces 2015, 7, 19619-19625. [CrossRef] [PubMed]

51. Zhong, H.X.; Wang, J.; Zhang, Y.W.; Xu, W.L.; Xing, W.; Xu, D.; Zhang, Y.F.; Zhang, X.B. ZIF-8 derived graphene-based nitrogen-doped porous carbon sheets as highly efficient and durable oxygen reduction electrocatalysts. Angew. Chem. Int. Ed. 2014, 53, 14235-14239. [CrossRef] [PubMed]

52. Thomas, M.; Illathvalappil, R.; Kurungot, S.; Nair, B.N.; Mohamed, A.A.P.; Anilkumar, G.M.; Yamaguchi, T.; Hareesh, U.S. Graphene oxide sheathed ZIF-8 microcrystals: Engineered precursors of nitrogen-doped porous carbon for efficient oxygen reduction reaction (ORR) electrocatalysis. ACS Appl. Mater. Interfaces 2016, 8, 29373-29382. [CrossRef] [PubMed]

53. Stamatin, S.N.; Hussainova, I.; Ivanov, R.; Colavita, P.E. Quantifying graphitic edge exposure in graphene-based materials and its role in oxygen reduction reactions. ACS Catal. 2016, 6, 5215-5221. [CrossRef]

54. Li, R.; Wei, Z.D.; Gou, X.L. Nitrogen and phosphorus dual-doped graphene/carbon nanosheets as bifunctional electrocatalysts for oxygen reduction and evolution. ACS Catal. 2015, 5, 4133-4142. [CrossRef]

55. Amiinu, I.S.; Zhang, J.; Kou, Z.K.; Liu, X.B.; Asare, O.K.; Zhou, H.; Cheng, K.; Zhang, H.N.; Mai, L.Q.; Pan, M.; et al. Self-organized 3D porous graphene dual-doped with biomass-sponsored nitrogen and sulfur for oxygen reduction and evolution. ACS Appl. Mater. Interfaces 2016, 8, 29408-29418. [CrossRef]

56. Li, Y.; Zhao, Y.; Cheng, H.H.; Hu, Y.; Shi, G.Q.; Dai, L.M.; Qu, L.T. Nitrogen-doped graphene quantum dots with oxygen-rich functional groups. J. Am. Chem. Soc. 2012, 134, 15-18. [CrossRef] [PubMed]

57. Fei, H.L.; Ye, R.Q.; Ye, G.L.; Peng, Z.W.; Fan, X.J.; Samuel, E.L.G.; Ajayan, P.M.; Tour, J.M. Boron- and nitrogen-doped graphene quantum dots/graphene hybrid nanoplatelets as efficient electrocatalysts for oxygen reduction. ACS Nano 2014, 8, 10837-10843. [CrossRef] [PubMed]

58. Jin, H.L.; Huang, H.H.; He, Y.H.; Feng, X.; Wang, S.; Dai, L.M.; Wang, J.C. Graphene quantum dots supported by graphene nanoribbons with ultrahigh electrocatalytic performance for oxygen reduction. J. Am. Chem. Soc. 2015, 137, 7588-7591. [CrossRef] [PubMed]

59. Higgins, D.C.; Hoque, M.A.; Hassan, F.; Choi, J.Y.; Kim, B.J.; Chen, Z.W. Oxygen reduction on graphene-carbon nanotube composites doped sequentially with nitrogen and sulfur. ACS Catal. 2014, 4, 2734-2740. [CrossRef]

60. Sui, Z.Y.; Meng, Y.N.; Xiao, P.W.; Zhao, Z.Q.; Wei, Z.X.; Han, B.H. Nitrogen-doped graphene aerogels as efficient supercapacitor electrodes and gas adsorbents. ACS Appl. Mater. Interfaces 2015, 7, 1431-1438. [CrossRef] [PubMed]

61. Ye, S.B.; Feng, J.C.; Wu, P.Y. Deposition of three-dimensional graphene aerogel on nickel foam as a binder-free supercapacitor electrode. ACS Appl. Mater. Interfaces 2013, 5, 7122-7129. [CrossRef] [PubMed]

62. Liu, C.G.; Yu, Z.N.; Neff, D.; Zhamu, A.; Jang, B.Z. Graphene-based supercapacitor with an ultrahigh energy density. Nano Lett. 2010, 10, 4863-4868. [CrossRef] [PubMed]

63. Wang, Y.; Shi, Z.Q.; Huang, Y.; Ma, Y.F.; Wang, C.Y.; Chen, M.M.; Chen, Y.S. Supercapacitor devices based on graphene materials. J. Phys. Chem. C 2009, 113, 13103-13107. [CrossRef]

64. Lee, J.H.; Park, N.; Kim, B.G.; Jung, D.S.; Im, K.; Hur, J.; Choi, J.W. Restacking-inhibited 3D reduced graphene oxide for high performance supercapacitor electrodes. ACS Nano 2013, 7, 9366-9374. [CrossRef] [PubMed]

65. Wang, B.; Liu, J.Z.; Zhao, Y.; Li, Y.; Xian, W.; Amjadipour, M.; MacLeod, J.; Motta, N. Role of graphene oxide liquid crystals in hydrothermal reduction and supercapacitor performance. ACS Appl. Mater. Interfaces 2016, 8, 22316-22323. [CrossRef] [PubMed]

66. Yoo, J.J.; Balakrishnan, K.; Huang, J.S.; Meunier, V.; Sumpter, B.G.; Srivastava, A.; Conway, M.; Reddy, A.L.M.; Yu, J.; Vajtai, R.; et al. Ultrathin planar graphene supercapacitor. Nano Lett. 2011, 11, 1423-1427. [CrossRef] [PubMed]

67. Lee, J.S.; Kim, S.I.; Yoon, J.C.; Jang, J.H. Chemical vapor deposition of mesoporous graphene nanoballs for Supercapacitor. ACS Nano 2013, 7, 6047-6055. [CrossRef] [PubMed]

68. Sahu, V.; Shekhar, S.; Sharma, R.K.; Singh, G. Ultrahigh performance supercapacitor from lacey reduced graphene oxide nanoribbons. ACS Appl. Mater. Interfaces 2015, 7, 3110-3116. [CrossRef] [PubMed] 
69. Han, J.W.; Zhang, L.L.; Lee, S.J.; Oh, J.H.; Lee, K.S.; Potts, J.R.; Ji, J.Y.; Zhao, X.; Ruoff, R.S.; Park, S.J. Generation of B-doped graphene nanoplatelets using a solution process and their supercapacitor applications. ACS Nano 2013, 7, 19-26. [CrossRef] [PubMed]

70. Wang, Z.G.; Chen, Y.F.; Li, P.J.; He, J.R.; Zhang, W.L.; Guo, Z.; Li, Y.R.; Dong, M.D. Synthesis of silicon-doped reduced graphene oxide and its applications in dye-sensitive solar cells and supercapacitors. RSC Adv. 2016, 6, 15080-15086. [CrossRef]

71. Xu, Z.W.; Li, Z.; Holt, C.M.B.; Tan, X.H.; Wang, H.L.; Amirkhiz, B.S.; Stephenson, T.; Mitlin, D. Electrochemical supercapacitor electrodes from sponge-like graphene nanoarchitectures with ultrahigh power density. J. Phys. Chem. Lett. 2012, 3, 2928-2933. [CrossRef] [PubMed]

72. Xie, B.H.; Yang, C.; Zhang, Z.X.; Zou, P.C.; Lin, Z.Y.; Shi, G.Q.; Yang, Q.H.; Kang, F.Y.; Wong, C.P. Shape-tailorable graphene-based ultra-high-rate supercapacitor for wearable electronics. ACS Nano 2015, 9 , 5636-5645. [CrossRef] [PubMed]

73. Wang, S.L.; Liu, N.S.; Su, J.; Li, L.Y.; Long, F.; Zou, Z.G.; Jiang, X.L.; Gao, Y.H. Highly stretchable and self-healable supercapacitor with reduced graphene oxide based fiber springs. ACS Nano 2017, 11, 2066-2074. [CrossRef] [PubMed]

74. Yu, G.H.; Hu, L.B.; Liu, N.; Wang, H.L.; Vosgueritchian, M.; Yang, Y.; Cui, Y.; Bao, Z.N. Enhancing the supercapacitor performance of graphene $/ \mathrm{MnO}_{2}$ nanostructured electrodes by conductive wrapping. Nano Lett. 2011, 11, 4438-4442. [CrossRef] [PubMed]

75. Naderi, H.R.; Norouzi, P.; Ganjali, M.R. Electrochemical study of a novel high performance supercapacitor based on $\mathrm{MnO}_{2}$ /nitrogen-doped graphene nanocomposite. Appl. Surf. Sci. 2016, 366, 552-560. [CrossRef]

76. Chen, H.; Zhou, S.X.; Wu, L.M. Porous nickel hydroxide-manganese dioxide-reduced graphene oxide ternary hybrid spheres as excellent supercapacitor electrode materials. ACS Appl. Mater. Interfaces 2014, 6, 8621-8630. [CrossRef] [PubMed]

77. He, Y.M.; Chen, W.J.; Li, X.D.; Zhang, Z.X.; Fu, J.C.; Zhao, C.H.; Xie, E.Q. Freestanding three-dimensional graphene $/ \mathrm{MnO}_{2}$ composite networks as ultralight and flexible supercapacitor electrodes. ACS Nano 2013, 7, 174-182. [CrossRef] [PubMed]

78. Liao, Q.Y.; Li, N.; Jin, S.X.; Yang, G.W.; Wang, C.X. All-solid-state symmetric supercapacitor based on $\mathrm{Co}_{3} \mathrm{O}_{4}$ nanoparticles on vertically aligned graphene. ACS Nano 2015, 9, 5310-5317. [CrossRef] [PubMed]

79. Heydari, H.; Gholivand, M.B. A novel high-performance supercapacitor based on high-quality $\mathrm{CeO}_{2} /$ nitrogen-doped reduced graphene oxide nanocomposite. Appl. Phys. A 2017, 123, 187. [CrossRef]

80. Quan, H.Y.; Cheng, B.C.; Xiao, Y.H.; Lei, S.J. One-pot synthesis of $\alpha-\mathrm{Fe}_{2} \mathrm{O}_{3}$ nanoplates-reduced graphene oxide composite for supercapacitor application. Chem. Eng. J. 2016, 286, 165-173. [CrossRef]

81. He, W.; Jiang, H.J.; Zhou, Y.; Yang, S.D.; Xue, X.; Zou, Z.Q.; Zhang, X.G.; Akins, D.L.; Yang, H. An efficient reduction route for the production of $\mathrm{Pd}-\mathrm{Pt}$ nanoparticles anchored on graphene nanosheets for use as durable oxygen reduction electrocatalysts. Carbon 2012, 50, 265-274. [CrossRef]

82. Stamenkovic, V.R.; Mun, B.S.; Arenz, M.; Mayrhofer, K.J.J.; Lucas, C.A.; Wang, G.F.; Ross, P.N.; Markovic, N.M. Trends in electrocatalysis on extended and nanoscale Pt-bimetallic alloy surfaces. Nat. Mater. 2007, 6, 241-247. [CrossRef] [PubMed]

83. Li, Y.; Kang, L.T.; Bai, G.L.; Li, P.Y.; Deng, J.C.; Liu, X.G.; Yang, Y.Z.; Gao, F.; Liang, W. Solvothermal synthesis of $\mathrm{Fe}_{2} \mathrm{O}_{3}$ loaded activated carbon as electrode materials for high-performance electrochemical capacitors. Electrochim. Acta 2014, 134, 67-75. [CrossRef]

84. Aravindan, V.; Mhamane, D.; Ling, W.C.; Ogale, S.; Madhavi, S. Nonaqueous lithium-ion capacitors with high energy densities using trigol-reduced graphene oxide nanosheets as cathode-active material. ChemSusChem 2013, 6, 2240-2244. [CrossRef] [PubMed]

85. Zhang, F.; Zhang, T.F.; Yang, X.; Zhang, L.; Leng, K.; Huang, Y.; Chen, Y.S. A high-performance supercapacitor-battery hybrid energy storage device based on graphene-enhanced electrode materials with ultrahigh energy density. Energy Environ. Sci. 2013, 6, 1623-1632. [CrossRef]

86. Wang, H.W.; Guan, C.; Wang, X.F.; Fan, H.J. A high energy and power Li-ion capacitor based on a $\mathrm{TiO}_{2}$ nanobelt array anode and a graphene hydrogel cathode. Small 2015, 11, 1470-1477. [CrossRef] [PubMed]

87. Xu, L.; Wang, S.L.; Zhang, X.; He, T.B.; Lu, F.X.; Li, H.C.; Ye, J.H. A facile method of preparing $\mathrm{LiMnPO}_{4} /$ reduced graphene oxide aerogel as cathodic material for aqueous lithium-ion hybrid Supercapacitors. Appl. Surf. Sci. 2018, 428, 977-985. [CrossRef] 
88. Aswathy, R.; Kesavan, T.; Kumaran, K.T.; Ragupathy, P. Octahedral high voltage $\operatorname{LiNi}_{0.5} \mathrm{Mn}_{1.5} \mathrm{O}_{4}$ spinel cathode: Enhanced capacity retention of hybrid aqueous capacitors with nitrogen doped grapheme. J. Mater. Chem. A 2015, 3, 12386-12395. [CrossRef]

89. Qian, Y.; Cai, X.Y.; Zhang, C.Y.; Jiang, H.F.; Zhou, L.J.; Li, B.S.; Lai, L.F. A free-standing $\mathrm{Li}_{4} \mathrm{Ti}_{5} \mathrm{O}_{12} /$ graphene foam composite as anode material for Li-ion hybrid supercapacitor. Electrochim. Acta 2017, 258, 1311-1319. [CrossRef]

90. Song, H.; Fu, J.J.; Ding, K.; Huang, C.; Wu, K.; Zhang, X.M.; Gao, B.; Huo, K.F.; Peng, X.; Chu, P.K. Flexible $\mathrm{Nb}_{2} \mathrm{O}_{5}$ nanowires/graphene film electrode for high-performance hybrid Li-ion supercapacitors. J. Power Sources 2016, 328, 599-606. [CrossRef]

91. Zhang, F.; Tang, Y.B.; Liu, H.; Ji, H.Y.; Jiang, C.L.; Zhang, J.; Zhang, X.L.; Lee, C.S. Uniform incorporation of flocculent molybdenum disulfide nanostructure into three-dimensional porous graphene as an anode for high-performance lithium ion batteries and hybrid supercapacitors. ACS Appl. Mater. Interfaces 2016, 8 , 4691-4699. [CrossRef] [PubMed]

(C) 2018 by the authors. Licensee MDPI, Basel, Switzerland. This article is an open access article distributed under the terms and conditions of the Creative Commons Attribution (CC BY) license (http://creativecommons.org/licenses/by/4.0/). 